\title{
Cloud thermodynamic phase detection with polarimetrically sensitive passive sky radiometers
}

\author{
K. Knobelspiesse ${ }^{1}$, B. van Diedenhoven ${ }^{2,4}$, A. Marshak $^{3}$, S. Dunagan ${ }^{1}$, B. Holben ${ }^{3}$, and I. Slutsker ${ }^{3,5}$ \\ ${ }^{1}$ NASA Ames Research Center, Moffett Field, CA, USA \\ ${ }^{2}$ NASA Goddard Institute for Space Studies, New York, NY, USA \\ ${ }^{3}$ NASA Goddard Space Flight Center, Greenbelt, MD, USA \\ ${ }^{4}$ Columbia University, New York, NY, USA \\ ${ }^{5}$ Sigma Space Corporation, Lanham, MD, USA \\ Correspondence to: K. Knobelspiesse (kirk.knobelspiesse@nasa.gov)
}

Received: 21 October 2014 - Published in Atmos. Meas. Tech. Discuss.: 2 December 2014

Revised: 27 February 2015 - Accepted: 27 February 2015 - Published: 24 March 2015

\begin{abstract}
The primary goal of this project has been to investigate if ground-based visible and near-infrared passive radiometers that have polarization sensitivity can determine the thermodynamic phase of overlying clouds, i.e., if they are comprised of liquid droplets or ice particles. While this knowledge is important by itself for our understanding of the global climate, it can also help improve cloud property retrieval algorithms that use total (unpolarized) radiance to determine cloud optical depth (COD). This is a potentially unexploited capability of some instruments in the NASA Aerosol Robotic Network (AERONET), which, if practical, could expand the products of that global instrument network at minimal additional cost.

We performed simulations that found, for zenith observations, that cloud thermodynamic phase is often expressed in the sign of the $Q$ component of the Stokes polarization vector. We chose our reference frame as the plane containing solar and observation vectors, so the sign of $Q$ indicates the polarization direction, parallel (positive) or perpendicular (parallel) to that plane. Since the fraction of linearly polarized to total light is inversely proportional to COD, optically thin clouds are most likely to create a signal greater than instrument noise. Besides COD and instrument accuracy, other important factors for the determination of cloud thermodynamic phase are the solar and observation geometry (scattering angles between 40 and $60^{\circ}$ are best), and the properties of ice particles (pristine particles may have halos or other features that make them difficult to distinguish from water droplets
\end{abstract}

at specific scattering angles, while extreme ice crystal aspect ratios polarize more than compact particles).

We tested the conclusions of our simulations using data from polarimetrically sensitive versions of the Cimel 318 sun photometer/radiometer that compose a portion of AERONET. Most algorithms that exploit Cimel polarized observations use the degree of linear polarization (DoLP), not the individual Stokes vector elements (such as $Q$ ). Ability to determine cloud thermodynamic phase depends on $Q$ measurement accuracy, which has not been rigorously assessed for Cimel instruments. For this reason, we did not know if cloud phase could be determined from Cimel observations successfully. Indeed, comparisons to ceilometer observations with a single polarized spectral channel version of the Cimel at a site in the Netherlands showed little correlation. Comparisons to lidar observations with a more recently developed, multi-wavelength polarized Cimel in Maryland, USA, show more promise. The lack of well-characterized observations has prompted us to begin the development of a small test instrument called the Sky Polarization Radiometric Instrument for Test and Evaluation (SPRITE). This instrument is specifically devoted to the accurate observation of $Q$, and the testing of calibration and uncertainty assessment techniques, with the ultimate goal of understanding the practical feasibility of these measurements. 


\section{Introduction}

The relationship between clouds and aerosols has long been recognized as one of the least certain components of the global climate, largely due to the difficulty of acquiring relevant global data sets (IPCC, 2013). This was the motivation for the establishment of the NASA Aerosol Robotic Network (AERONET), which is chiefly devoted to the measurement of atmospheric aerosols by the use of sun photometer/sky radiometers manufactured by Cimel, Inc. (Holben et al., 1998). These instruments typically "sleep" when clouds obscure the sun, but select instruments also collect data while pointed in the zenith direction. Data collected in this "cloud mode" are used to determine cloud optical depth (COD) and cloud fraction (Marshak et al., 2000, 2004; Barker and Marshak, 2001; Chiu et al., 2006, 2010). This algorithm relies on the spectral contrast between blue (or red) and near-infrared reflectances of vegetated surfaces surrounding the measurement site and employs a lookup table (LUT) of precomputed radiances to match observations to retrieved parameters. These LUTs are generated for a cloud with a known thermodynamic phase, liquid or ice, and the use of the incorrect LUT can lead to very large retrieval errors. An example from the recent DRAGON field campaign (Distributed Regional Aerosol Gridded Observation Networks; white paper: http://aeronet.gsfc.nasa.gov/new_web/Documents/ DRAGON_White_Paper_A_system_of_experiment.pdf)

found this to be a problem. Cloud mode retrievals were performed that were consistent with a COD of 18 for an ice phase cloud, but 30 for a water phase cloud (S. Huang, personal communication, 2012). Since this uncertainty is significant, we have searched for methods to determine cloud thermodynamic phase from instruments operating in cloud mode.

A portion of the Cimel instruments used by AERONET are sensitive to linearly polarized radiation. The first polarization-sensitive Cimel instruments were constructed with sensitivity in a single channel $(870 \mathrm{~nm})$, while more recent versions are sensitive in all channels (typically 400, 500, $675,870,1020$ and $1640 \mathrm{~nm}$ ). Clear-sky measurements from these instruments are primarily used to determine aerosol optical properties (Li et al., 2004, 2006, 2007, 2009, 2010, 2013, 2009). Often, these algorithms use measures of quantity of polarization, and discard linear polarization direction information. Our goal is to determine if polarimetric observations made by AERONET instruments operating in the cloud mode can be used to identify cloud thermodynamic phase, and therefore improve the retrieval of cloud properties by selecting the proper LUT. We believe this is possible with the direction of linear polarization, which can be determined with the Cimel but is not often used. This paper is subsequently divided into three main sections. The next section (Sect. 2) describes the results of vector radiative transfer simulations of ice and liquid phase clouds as observed by ground radiometers such as the Cimels employed by AERONET.

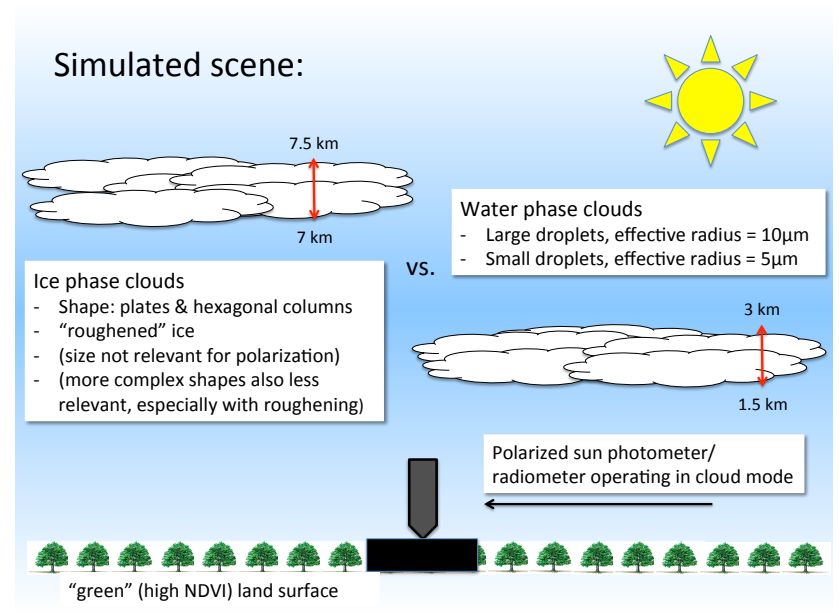

Figure 1. Illustration of the simulated scene. Sky radiances were generated for a variety of solar zenith angles $\left(15,30,45\right.$ and $\left.60^{\circ}\right)$, cloud optical depths $(2.5,5,7.5,10,15,20$ and 30) and ice particle or cloud droplet types (see Section 2). Surface reflectance was provided by observations of a high normalized difference vegetation index (NDVI) from late summer in central Oklahoma (Knobelspiesse et al., 2008).

Section 3 contains an analysis of actual AERONET polarized cloud observations and comparison to independent data sets that serve as proxies to cloud thermodynamic phase. Section 4 discusses the previous two sections and makes recommendations for future observations. We conclude in Sect. 5. Additionally, Appendix A provides an uncertainty analysis for these types of measurements.

\section{Simulations}

We began by performing simulations of a cloud-atmosphere system, utilizing a vector (polarimetric) radiative transfer model developed at NASA Goddard Institute for Space Studies (GISS). This model uses the doubling and adding technique to compute multiple scattering in a plane-parallel system (de Haan et al., 1987). Single scattering properties were computed as the Lorenz-Mie solution of Maxell's equations (Hansen and Travis, 1974) for spherical liquid water droplets, or for randomly oriented, "roughened" hexagonal ice plates or columns using geometric optics (Macke et al., 1996). Figure 1 is an illustration describing the simulated scenes, which were performed at a variety of CODs $(2.5,5,7.5,10,15$, 20 and 30$)$ and solar zenith angles $\left(15,30,45\right.$ and $\left.60^{\circ}\right)$. Ice phase clouds, which were lofted between 7 and $7.5 \mathrm{~km}$ in a standard atmosphere, were simulated with ice particle aspect ratios (ARs; the ratio of height to width) of $0.05,1,2$ and 20 and roughness parameters (Macke et al., 1996) of 0 (pristine) and 0.4. Although natural clouds generally contain more complex ice crystals, the scattering properties of single hexagonal prisms closely resemble those of such com- 
plex structures (Baran, 2009; Um and McFarquhar, 2007, 2009; van Diedenhoven et al., 2014). Since ice clouds can be simulated with geometric scattering for visible and nearinfrared wavelengths, particle size is minimally relevant for fixed COD. Liquid phase clouds were simulated at lower altitudes (between 1.5 and $3 \mathrm{~km}$ ) for droplets with effective radii of 10 and $5 \mu \mathrm{m}$. To correspond with AERONET instrument spectral channels, these simulations were performed at 440, 500, 560, 675, 870, and $1020 \mathrm{~nm}$. These channels were also chosen so that they are minimally affected by atmospheric gas absorption. Total column pressure was $1013.25 \mathrm{mb}$, and ground temperature $288.15^{\circ} \mathrm{K}$. COD retrieval from cloud mode radiometers uses the spectral contrast of surface reflectance, which works best when that surface is very "green", expressed as a high normalized difference vegetation index (NDVI). We therefore chose a surface spectral reflectance from vegetated surface measurements in late summer in central Oklahoma (Knobelspiesse et al., 2008). To test the sensitivity to these model conditions, we also performed simulations with modified altitude profiles and surface reflectances, and individually simulated a cloud with mixed liquid and ice phase.

Simulation results were expressed as the Stokes polarization vector, $\boldsymbol{I}=[I, Q, U, V]$, observed by a noiseless, upwards-looking radiometer at the ground. We present these values as unitless, and equivalent to reflectance that would be observed by a downwards-looking instrument, i.e.,

$$
\boldsymbol{R}=\frac{\boldsymbol{I} \pi r_{o}^{2}}{F_{o} \cos \theta_{s}}
$$

where $\boldsymbol{I}$ is the Stokes vector in radiance [W $\left.\mathrm{m}^{-2} \mathrm{sr}^{-1}\right], r_{o}$ is the solar distance in astronomical units [AU] (we used $\left.r_{o}=1\right), F_{o}$ is the exo-atmospheric irradiance $\left[\mathrm{W} \mathrm{m}^{-2}\right]$ at a solar distance of $\mathrm{AU}=1$, and $\theta_{\mathrm{S}}$ is the solar zenith angle. Generally speaking, the $I$ component of the Stokes vector expresses the total reflectance, $Q$ and $U$ express the magnitude and direction of linear polarization, and $V$ the circular polarization. For scattered solar light in the atmosphere at visible and near-infrared wavelengths, $V$ is small $(<0.2 \%$ of linear polarization; de Haan et al., 1987; Kawata, 1978), so we restrict ourselves in this analysis to the first three Stokes vector elements, $[I, Q, U]$. This subset of the Stokes vector is also relatively simple to observe, and is easily obtained from direct measurements. The Cimel radiometers use linearly polarizing filters at different orientations, so that the linearly polarizing component of the Stokes vector is computed as

$$
\boldsymbol{I}=\left[\begin{array}{c}
I \\
Q \\
U
\end{array}\right]=\left[\begin{array}{c}
\frac{2}{3}\left(\hat{I}\left(0^{\circ}\right)+\hat{I}\left(120^{\circ}\right)+\hat{I}\left(240^{\circ}\right)\right) \\
\frac{2}{3}\left(2 \hat{I}\left(0^{\circ}\right)-\hat{I}\left(120^{\circ}\right)-\hat{I}\left(240^{\circ}\right)\right) \\
\frac{2}{\sqrt{3}}\left(\hat{I}\left(240^{\circ}\right)-\hat{I}\left(120^{\circ}\right)\right)
\end{array}\right]
$$

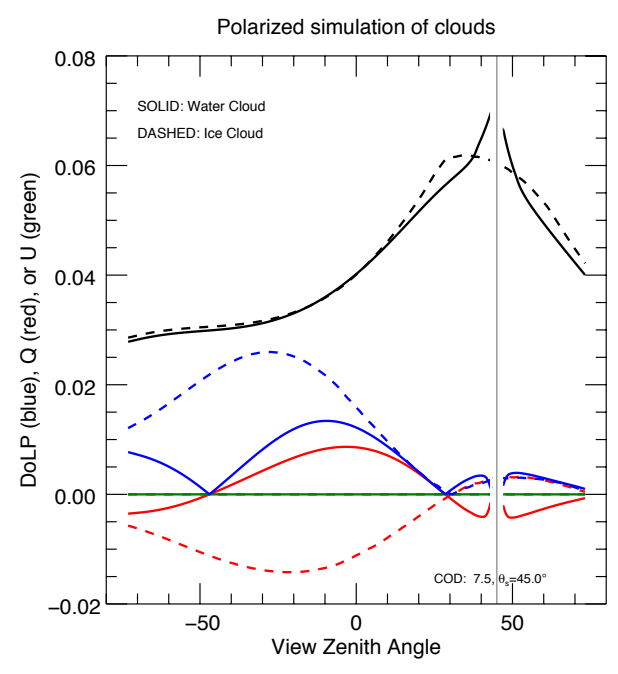

Figure 2. Simulated ground observation of a liquid and ice phase cloud in the solar principal plane. The simulation wavelength was $870 \mathrm{~nm}, \mathrm{COD}$ was 7.5 , and solar zenith angle $45^{\circ}$. The water cloud (solid lines) had droplets with an effective radius of $10 \mu \mathrm{m}$, while the ice cloud (dashed lines) was comprised of crystals with an aspect ratio of 20 and roughness parameter of 0.4 . Both simulations used an isotropic surface reflectance of 0.391 , which was observed at $870 \mathrm{~nm}$ for a vegetated surface by Knobelspiesse et al. (2008). DoLP (blue), $Q$ (red), and $U$ (green) are expressed with the axis on the left, while $I$ (black) with the axis on the right. Values within $2^{\circ}$ of the incoming solar direction $\left(45^{\circ}\right.$, indicated by the thin vertical line) were omitted for graphical clarity.

where $\hat{I}(X)$ indicates the radiance observed in a Cimel channel with a linear polarizer oriented at $X^{\circ}$ from the reference plane (which is typically chosen at the solar principal plane, containing both the solar illumination and observation direction vectors)(Chandrasekhar, 1960).

A common polarization metric is the degree of linear polarization (DoLP):

$\operatorname{DoLP}=\frac{\sqrt{Q^{2}+U^{2}}}{I}=\frac{\sqrt{R_{Q}^{2}+R_{U}^{2}}}{R_{I}}$,

which is used as a means to represent the quantity of linear polarization in a scene independent of reference frame. This presents an advantage because of simplicity and diminished sensitivity to calibration uncertainty and errors in filter orientation $(X)$, but also means information about polarization direction has been discarded. As we shall see, polarization direction most clearly expresses cloud thermodynamic phase, so we are compelled to avoid DoLP. Note that, in Eq. (3), $R_{I}$, $R_{Q}$, and $R_{U}$ indicate the $I, Q$, and $U$ elements of the vector $\boldsymbol{R}$ defined in Eq. (1).

\subsection{Simulation results}

Figure 2 is an example of the typical polarization encountered with water (solid) and ice (dashed) clouds as observed 

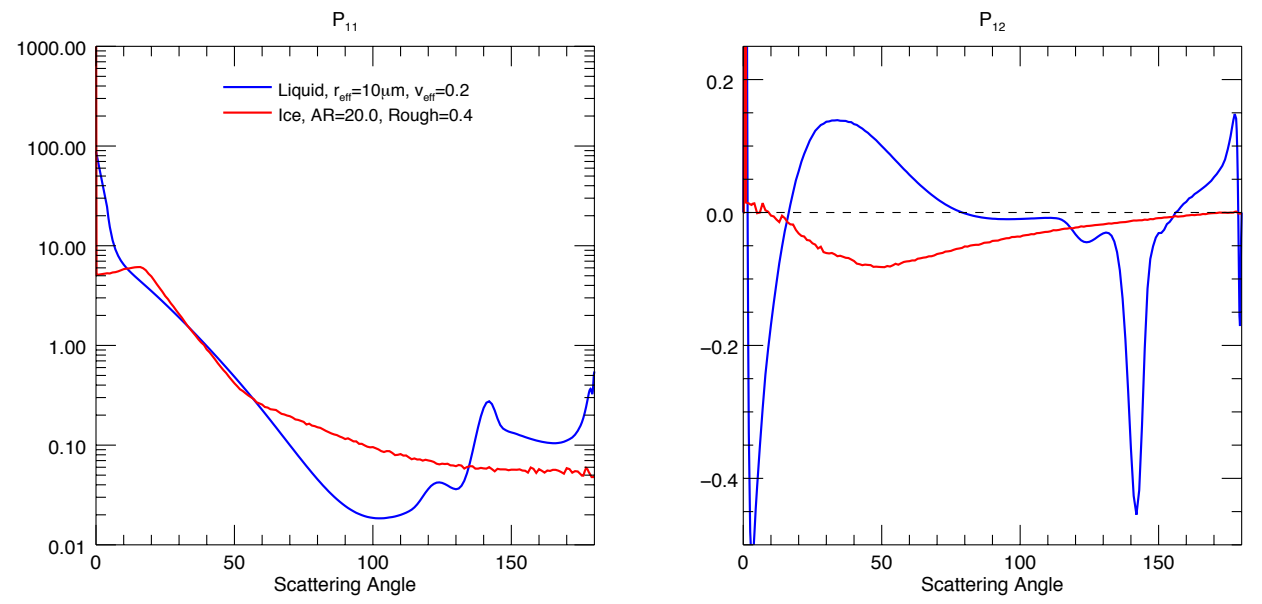

Figure 3. Example $P_{11}$ and $P_{12}$ phase matrix elements for water (blue) and ice (red) clouds. The $P_{11}$ element, which generates scattering from unpolarized radiation for the $I$ Stokes vector component, is quite similar for water and ice clouds at typical scattering angles for ground observation (less than $70^{\circ}$ ). Conversely, the $P_{12}$ element, which generates scattering from unpolarized radiation for the $Q$ Stokes vector component, has a different sign for most observable scattering angles. As we have seen in Fig. 2, this sign difference is maintained with multiple scattering. Note that both $P_{11}$ and $P_{12}$ are strongly forward-scattering, but that this peak is beyond the plotting range for $P_{12}$.

by a narrow-field-of-view (FOV) ground radiometer at a variety of zenith angles in the solar principal plane. $I$ is generally at least an order of magnitude larger than DoLP or $Q$ (note the axes). There are no systematic (for different clouds) distinctions between water and ice phase clouds in $I$ or DoLP, especially for zenith observations. However, the $Q$ of water and ice clouds have opposite signs at most angles, meaning that polarization direction differs. For these reasons, we believe $Q$ is the best means to determine cloud thermodynamic phase when defined in the solar principal plane as it is here. $U$ is many orders of magnitude smaller than DoLP or $Q$, meaning that it contains little information about clouds. As we shall see later, we use this property of $U$ to ensure that we have properly identified the solar principal plane. We could, of course, also describe the polarization direction by the polarization angle, $\chi=\frac{1}{2} \tan ^{-1}(U / Q)$. The convention from Hansen and Travis (1974) for $\chi$ is to select the value in the interval $0 \leq \chi<\pi$ where the sign of $\cos (2 \chi)$ and $Q$ are the same. Because uncertainty and numerical issues are easier to track, we will express the results of our simulations and analysis in $Q$.

The polarization direction difference between liquid and ice phase clouds is inherent to the single scattering properties of water droplets and ice crystals. We can see this by plotting the $P_{11}$ and $P_{12}$ phase matrix elements, as we have done in Fig. 3. The phase matrix, $\boldsymbol{P}$, transforms an incoming wave of radiation (such as unpolarized solar radiation, $\left.\boldsymbol{I}_{o}=[1,0,0,0]\right)$ to the scattered wave at a scattering angle, $\gamma$, such that

$\boldsymbol{I}(\gamma)=k_{\mathrm{e}} \varpi \frac{d v}{4 \pi R^{2}} \boldsymbol{P}(\gamma) \boldsymbol{I}_{o}$, where $d v$ is the scattering volume, $k_{\mathrm{e}}$ is the extinction coefficient, $\varpi$ is the single scattering albedo (the ratio of scattering to total extinction), and $R$ is the distance from $d v$ to the observation location. Thus, the $P_{11}$ element describes the transfer from $\boldsymbol{I}_{o}$ to $\boldsymbol{I}$, while $P_{12}$ the transfer of $\boldsymbol{I}_{o}$ to $Q$. Figure 3 shows us that, at scattering angles relevant to ground observation (roughly $10^{\circ}<\gamma<70^{\circ}$ ), liquid and ice phase clouds are not dramatically different for $P_{11}$, but have different sign for $P_{12}$.

Figure 2 also indicates that there is a polarization neutral point roughly $15^{\circ}$ above the solar direction. This neutral point persists, with minor variation, for all cloud types (liquid or ice). The only exception was for pristine (non-roughened) ice clouds, which only have neutral points near halos. Unlike the cloudless (Rayleigh scattering dominated) sky, single scattering properties are the origin of this neutral point. This can be see by the $P_{12}$ zero crossing at roughly $15^{\circ}$ on the right in Fig. 3. Because of this, we can also expect a second neutral point $15^{\circ}$ below the solar direction, which is observable in simulations performed at solar zenith angles of $\theta_{\mathrm{s}}=15^{\circ}$ and $\theta_{\mathrm{s}}=30^{\circ}$.

Figure 4 shows the type of measurements that groundbased, zenith-viewing polarimeters would make of ice and liquid clouds with various COD. The $Q$ Stokes vector element, on the left, clearly expresses the distinction between liquid and ice phase clouds. The reference frame defining $Q$ is the solar principal plane, where the value of $U$ is very small. The DoLP, on the right, is nearly equivalent to the absolute value of $Q$, so the distinction between water and ice phase is lost. Both $Q$ and DoLP show the most polarization for the smallest COD, meaning that the ability to determine thermodynamic phase diminishes for thicker clouds. We can also see that the largest (negative) polarization for ice clouds 

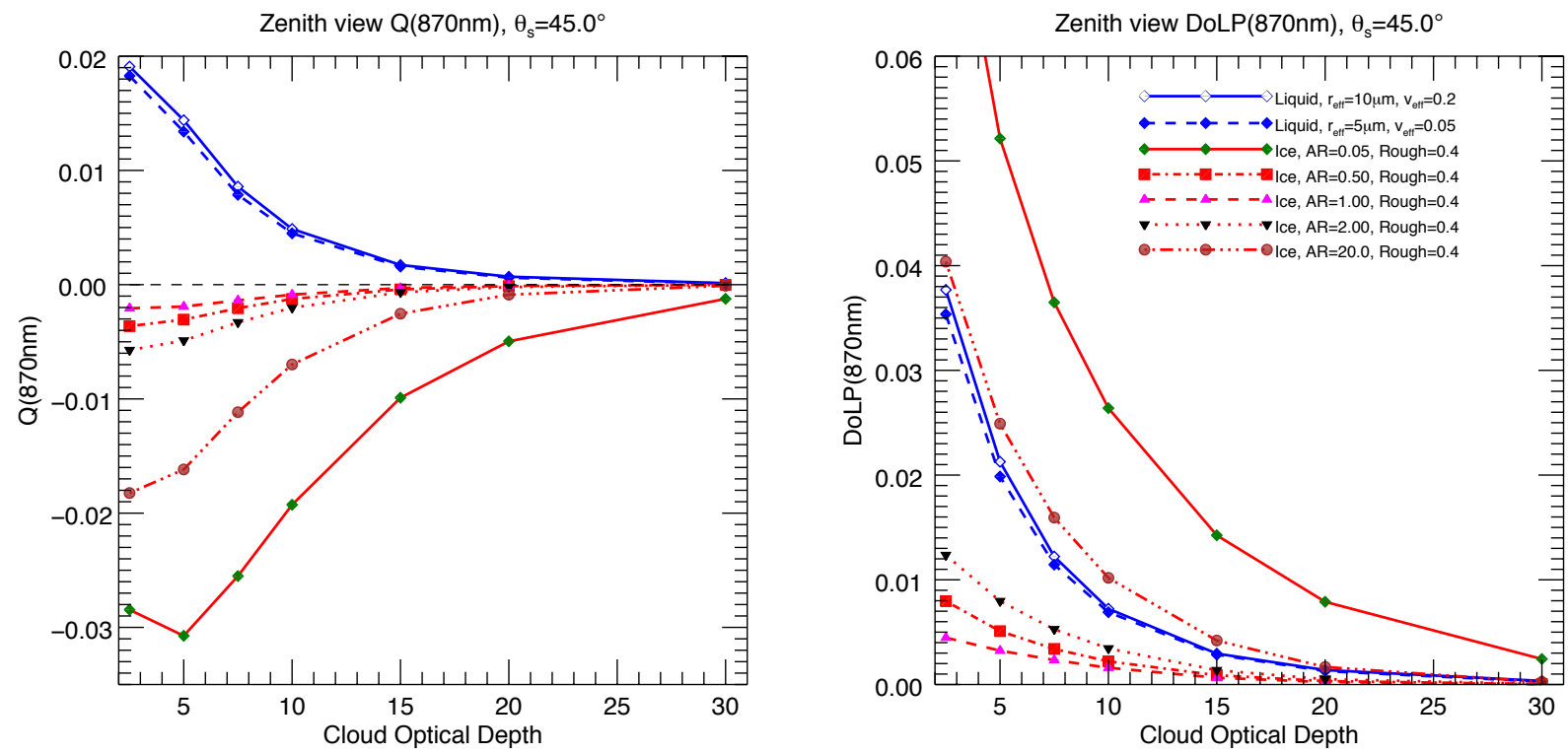

Figure 4. Simulated $Q$ (left) and DoLP (right) for liquid (blue) and ice (red) phase clouds observed from the ground by a polarimeter observing in the zenith direction at $870 \mathrm{~nm}$ and with a solar zenith angle of $\theta_{\mathrm{s}}=45^{\circ}$.

is generated for crystals with the most extreme AR). Based on so-called "directional memory", the original radiative direction is lost after $1 /(1-g)$ orders of scattering, and thereafter travels isotropically (Davis and Marshak, 2002) (here, $g$ is the asymmetry factor, the first moment of the $P_{11}$ phase matrix element). If we assume a multiplicative coefficient of proportionality of 2 , and a liquid cloud $g=0.85$, loss of directional memory occurs at $\mathrm{COD}=\frac{2}{1-g}=\frac{2}{1-0.85}=13.3$ or greater. Figure 4 is consistent with this relationship, since $Q$ and DoLP, as expressions of directionality, converge to 0 for roughly COD $>13$.

\subsection{Observability}

Figure 4 makes a compelling case for the observability of cloud thermodynamic phase with polarization, but several factors affect the ability to make this distinction with real observations. Instrument uncertainty is of utmost importance, yet it often remains uncharacterized for $Q$ and $U$ (Appendix $\mathrm{A}$ is an uncertainty characterization of an instrument that uses linearly polarizing filters, such as the Cimel radiometers used by AERONET). Geophysical characteristics of the scene are also important. Factors such as the solar zenith angle (or, more directly, the scattering angle) play a role, and the presence of halos or other features of pristine ice crystals can also interfere with with cloud phase determination. Below, we will further investigate sensitivity to these details. On the other hand, factors which are typically important for remote sensing of clouds from the ground, such as the need to account for nearby surface reflectance and cloud base height, are relatively unimportant.
Figure 5 shows the scattering angle dependence of $Q$ at $870 \mathrm{~nm}$ for liquid and ice clouds for a variety of simulated solar zenith angles. Here, we define scattering angle as the angle between the solar illumination direction and the scattered direction. Results from simulations with a variety of solar zenith angles show similar behavior, indicating that the scattering angle largely defines $Q$. The liquid cloud is most polarizing at scattering angles roughly between 40 and $50^{\circ}$, while ice clouds are most (negatively) polarizing at angles between 60 and $70^{\circ}$. Differentiation between liquid and ice clouds is therefore best performed in this range, where scattering angles are between 40 and $70^{\circ}$. For zenith measurements, the solar zenith angle is the scattering angle, meaning that phase differentiation is best when solar zenith angle is between 40 and $70^{\circ}$, and improbable when it is less than $20^{\circ}$. If a ground-based radiometer has the ability to control pointing direction, the optimal measurement would not necessarily be made at zenith, but in a direction in the solar principal plane roughly $55^{\circ}$ from the sun.

The linearly polarized scattering of ice crystals $\left(P_{12}\right.$, the right panel in Fig. 3) is primarily dependent upon AR and surface roughness (randomization of scattering) (van Diedenhoven et al., 2012). Figure 6 shows $P_{12}$ of drops and ice crystals with varying aspect ratios. Here, variations in ice size are not considered since ice crystals are generally large enough for their scattering properties to be simulated with geometric optics (Bi et al., 2014), and thus size has a minimal impact on $P_{12}$. Note, however, that aspect ratio could depend on size (Auer Jr and Veal, 1970; Um et al., 2014). Cloud chamber, in situ, and remote sensing observations indicate that distorted, roughened ice crystals are generally prevalent (Baran, 2009; van Diedenhoven et al., 2013; Pfalzgraff et al., 


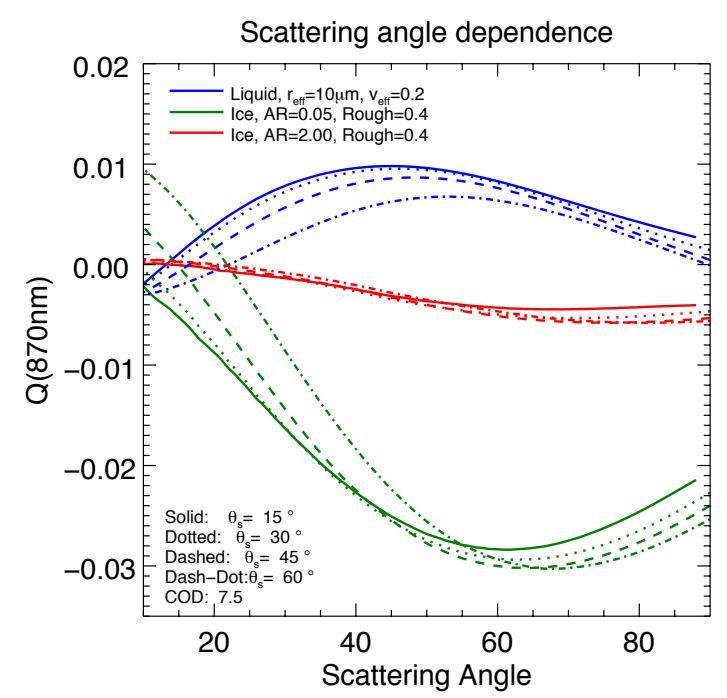

Figure 5. Simulated $Q$ as a function of scattering angle (defined as the angle from the solar incidence direction) for a liquid cloud (blue), ice cloud with an extreme aspect ratio (green), and an ice cloud with a more compact aspect ratio (red). The line style indicates the simulation solar zenith angle.

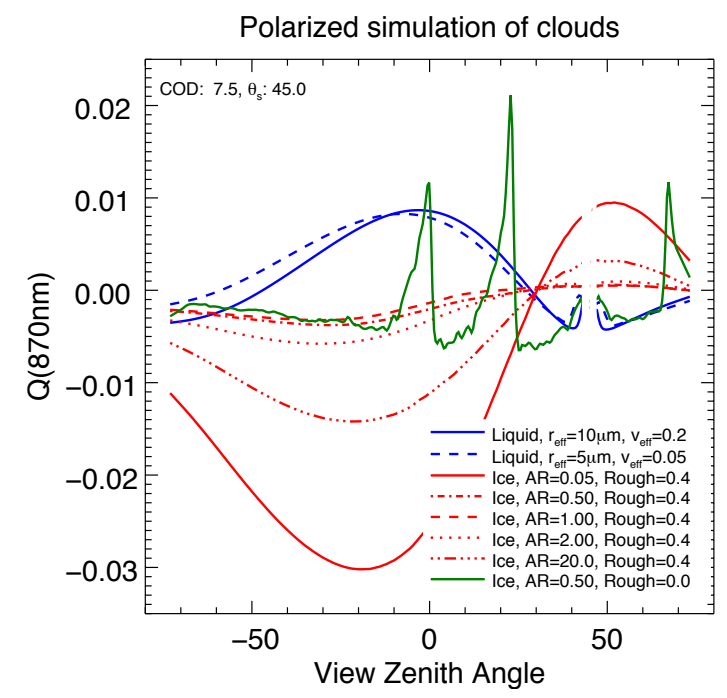

Figure 6. Simulated $Q$ with respect to view zenith angle for liquid (blue) and ice clouds, including an ice cloud comprised of pristine crystals (green, roughened crystal clouds are shown in red). The roughness factor, which is 0 for pristine crystals and increases with surface facet randomization, is defined according to Macke et al. (1996). Both the 22 and $46^{\circ}$ halos (at zenith angles of roughly 23 and $67^{\circ}$ for the $22^{\circ}$ halo, and $0^{\circ}$ for the $46^{\circ}$ halo) are clear for the pristine ice crystal cloud.

2010; Magee et al., 2014). Therefore, we performed our simulations with crystals that have been roughened. However, pristine ice crystals do exist in clouds, as is indicated by the frequent observation of halos from the ground (Sassen et al., 2003; van Diedenhoven, 2014). Observations performed at

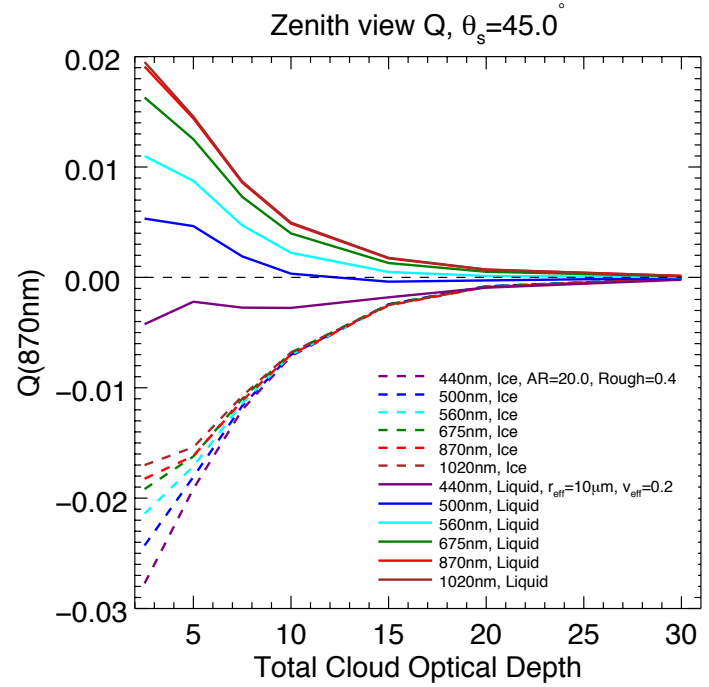

Figure 7. Spectral dependence of simulated $Q$ as a function of cloud optical depth. The linear polarization of liquid clouds $\left(r_{\mathrm{eff}}=\right.$ $20 \mu \mathrm{m}, v_{\text {eff }}=0.2$ shown here) changes significantly for different wavelengths. $Q$ is smaller as wavelength decreases, and the shortest wavelength, $440 \mathrm{~nm}$, is negative. Ice clouds are more uniform for the various simulated spectral channels. Like liquid clouds, ice clouds $(\mathrm{AR}=20$, roughness $=0.4$ shown here) have more negative values of $Q$ as wavelength is decreased.

some combinations of viewing and solar zenith angles mean that these halos would be directly measured. As is shown in Fig. 6, the halo value of $Q$ spikes above 0, meaning that it looks similar to liquid phase clouds. Lacking other observations, ice clouds at this geometry would be confused for liquid phase clouds. From a measurement perspective, the halo at $46^{\circ}$ is potentially the most problematic, since the $22^{\circ}$ halo is already at a scattering angle where it is difficult to distinguish liquid from ice clouds. However, the $46^{\circ}$ halo is very rarely observed and only occurs when the cloud is comprised of a large fraction of pristine particles (van Diedenhoven, 2014). Furthermore, the simulation of completely pristine crystals shown here must be considered as a limiting case, since some level of distortion or roughening is likely for crystals in most halo-producing cirrus clouds (Shcherbakov, 2013; van Diedenhoven, 2014).

The spectral dependence for selected visible and nearinfrared channels (corresponding to multiple polarized channel Cimel wavelengths) is shown in Fig. 7. As we can see, the cloud thermodynamic phase linear polarization direction effect (expressed as $Q$ ) is largely preserved at different wavelengths. Generally, $Q$ decreases as wavelength decreases, such that $Q(440 \mathrm{~nm})$ for liquid phase clouds is less than 0 in the most extreme case. Simulations of liquid clouds comprised by other size droplets are nearly identical to the single liquid cloud shown in the figure, while different aspect ratio ice clouds show similar spectral dependence but varying absolute magnitudes of $Q$ (similar to what is shown in Fig. 4). 

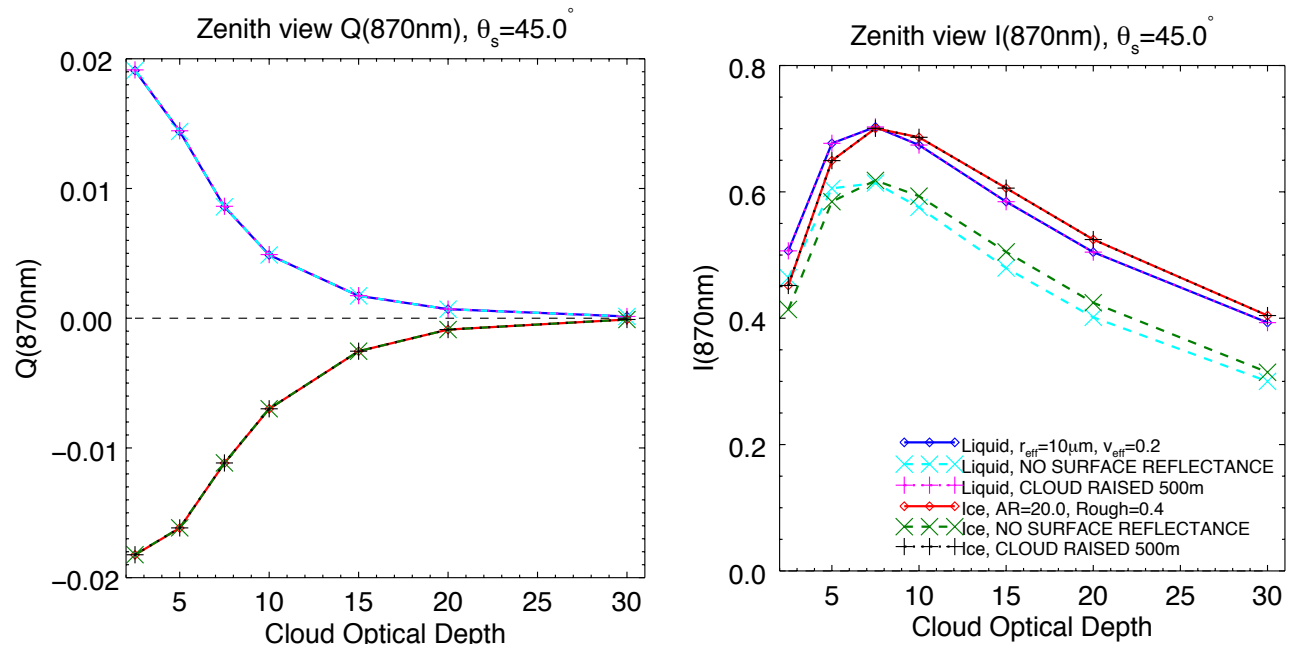

Figure 8. Simulated $Q$ (left) and $I$ (right) for liquid (blue, cyan, magenta) and ice (red, green, black) phase clouds observed from the ground by a polarimeter observing in the zenith direction at $870 \mathrm{~nm}$ and with a solar zenith angle of $\theta_{\mathrm{S}}=45^{\circ}$. Both the liquid and ice clouds were simulated with different surfaces reflectances (cyan and green) and altitudes (magenta and black). The left-most plot illustrates the lack of sensitivity to these changes for $Q$, while sensitivity to surface reflectance for $I$ is shown on the right. Cloud base height does not strongly affect either $Q$ or $I$.

For both ice and liquid clouds, observations of $Q$ are insensitive to factors that typically affect $I$, such as cloud vertical distribution and surface reflectance. This is illustrated in Fig. 8, where these properties have been modified, and have no noticeable effect on $Q . I$, in contrast, is quite sensitive to surface reflectance, particularly at $870 \mathrm{~nm}$, where vegetated surfaces can be quite bright. In fact, this forms the basis of the cloud optical depth retrieval algorithms used by AERONET (Chiu et al., 2006, 2010). The sensitivity to vertical distribution increases with increased Rayleigh scattering at shorter wavelengths, but the impact of this on $Q$ remains minimal.

We also performed simulations for mixed-phase clouds. Figure 9 shows the transition from negative to positive values of nadir observed $Q$ for a cloud with liquid on the bottom and ice on the top. While this transition is gradual, it should be noted that the cloud with $50 \%$ liquid and $50 \%$ ice has negative values of $Q$ for all simulated values of total COD. If the sign of $Q$ is used to identify cloud thermodynamic phase, this cloud would be identified as one comprised of ice.

To conclude, we have simulated a variety of ice and liquid phase clouds, and found that the linear polarization direction, expressed as the sign of the $Q$ element of the Stokes polarization vector (defined in the scattering plane), indicates thermodynamic phase. The utility of this distinction is dependent upon the total COD (thinner clouds polarize more), the solar and observational viewing geometry (scattering angles between 40 and $70^{\circ}$ are best), ice crystal aspect ratio (values close to $\mathrm{AR}=1.0$ polarize least), and the instrument accuracy with respect to $Q$. Additionally, the ability to determine cloud thermodynamic phase with polarization is insensitive to the altitude of the cloud or the surface reflectance.

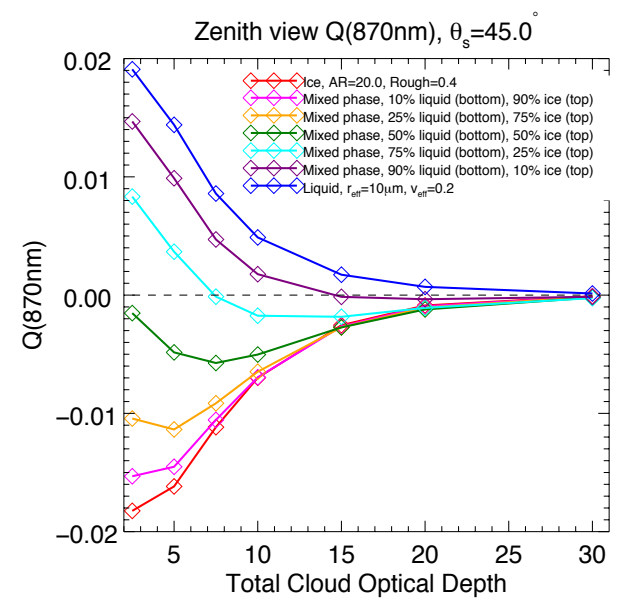

Figure 9. Nadir observed $Q(870 \mathrm{~nm})$ at varying CODs for an ice phase cloud (red), liquid phase cloud (blue), and mixed-phased clouds. The mixed-phase clouds have the liquid phase on the bottom and ice on the top, mixed in percentages of total COD. The simulated solar zenith angle was $\theta_{\mathrm{s}}=45^{\circ}$.

There are many ways to determine cloud thermodynamic phase from the ground, such as with active measurements (Sassen, 1991), spectral ratios (Martins et al., 2011; LeBlanc et al., 2014), hyperspectral infrared measurements (Turner et al., 2003), and microwave radiometers (Shupe et al., 2005; Campos et al., 2014). While it may not be appropriate for all conditions, this method is well suited for low CODs, which may be a useful addition to the observational toolset. It also can be performed by AERONET instruments when they observe clouds, with no modification other than to measure- 
ment protocol. AERONET instruments have been deployed in hundreds of locations throughout the world for more than a decade (Holben et al., 1998), and our simulations show that data from the polarized instruments in the network could potentially provide information on cloud thermodynamic phase as well.

\section{Data exploration}

We tested our simulations with AERONET Cimel data collected at two sites that have co-located independent observations of proxies to cloud thermodynamic phase. Each site employed a different version of the Cimel instrument. An early variant of the instrument, which has polarization sensitivity in a single channel centered at $870 \mathrm{~nm}$, has been deployed at the Cabauw Experimental Site for Atmospheric Research (CESAR, www.cesar-observatory.nl) in the Netherlands since 2010. A variety of other instrumentation is also located at CESAR, including infrared radiometers and lidars that can determine cloud base height and, by inference, thermodynamic phase. A more recent version of the Cimel, with polarized channels at 440, 500, 675, 870, 1020 and $1640 \mathrm{~nm}$, has been deployed at the NASA Goddard Space Flight Center (GSFC) in suburban Washington, DC. NASA GSFC is the AERONET base of operations and is also where lidars are frequently deployed.

In 2014, AERONET deployed 515 instruments, of which 29 have a single polarized channel and 19 are the more recent version with multiple polarization-sensitive channels.

Both versions of the Cimel instrument are primarily employed to measure the DoLP. Since DoLP is insensitive to the orientation of the linearly polarizing filters, the measurement reference plane (as in Eq. 2) does not need to be known. Our simulations, however, indicate that DoLP does not contain information about cloud thermodynamic phase, while $Q$, defined in the solar principal plane, does (Fig. 4). Since reference frame is relevant to the determination of $Q$, we need to know it accurately for AERONET. Standard operation of AERONET instruments does not require such knowledge, so we attempted to confirm our knowledge of instrument orientation with observations of $U$. This is equivalent to the method in Li et al. (2009), who identify the reference frame by ensuring the polarization angle, $\chi$, of skylight is consistently $90^{\circ}$ from the scattering plane. In the Appendix, we explore how polarizing filter orientation knowledge accuracy impacts overall measurement uncertainty.

\subsection{Single-channel polarimeter site: CESAR}

We tested the ability of the single polarized channel AERONET Cimel to determine cloud phase with data from the CESAR site. This site was selected because of the variety and frequency of cloudy conditions, both stratiform and convective, encountered in the Netherlands and the availabil- ity of coincident data that can indicate cloud thermodynamic phase. A Vaisala LD-40 ceilometer (which indicates cloud base height; Muenkel et al., 1999, 2002) was positioned at the site. Since cloud drops generally freeze at increased altitudes where the temperatures falls to somewhere between -20 and $-40^{\circ} \mathrm{C}$ (Riédi et al., 2001; Hogan et al., 2003; Westbrook and Illingworth, 2011), data from this instrument (along with radiosonde temperature data) can be used to roughly estimate cloud thermodynamic phase.

To analyze these data, we first needed to find the Cimel linearly polarizing filter reference frame. Once it was known, we could determine the Stokes vector (Eq. 2) as defined in that frame and then "rotate" the Stokes vector from its observed frame to the solar principal plane (see Eq. 3.15 in Hansen and Travis, 1974). When defined in the solar principal plane, nearly all polarization should be expressed in the $Q$ Stokes vector element, and $U$ would be minimal (Fig. 2 is an example of this).

Since we had no information about the polarizing filter reference frame, we started with the assumption that they were oriented in the solar principal plane. To test this, we made a scatterplot of $Q$ and $U$ for the entire data set. If our assumption has been correct, we could have expected to see no correlation between $Q$ and $U$, and a wider range of $Q$ values than $U$ values. As we can see from the left-most plot in Fig. 10, this was not the case. If, however, the expected frame of reference is rotated by $16^{\circ}$, we can find a more appropriate relationship between $Q$ and $U$. This particular angle is most likely due to instrument operation specifics. In this case, the instrument is probably aligned to the solar principal plane while in the "park" mode, and it rotates slightly out of the principal plane to avoid a locking mechanism while moving into the zenith-viewing mode. We therefore used this reference frame for all subsequent analysis and performed a similar test for the multiple-spectral-channel instrument described in the next subsection. The shape of these histograms is also somewhat disturbing. For successful determination of cloud thermodynamic phase, we would hope to see a far wider range of $Q$ than $U$ values. The more compact shape of these histograms indicates the potential for large uncertainties in $Q$ and $U$.

To illustrate the potential for cloud thermodynamic phase determination, we looked for days in the AERONET data set at CESAR that had both ice and water phase clouds. This was done so that we could show $Q$ changing with cloud phase. While this does not indicate the overall viability of this technique, it provides a detailed look at the evolution of $Q$ in response to cloud conditions. Figure 11 displays one such day, 3 February 2013. The day began with highaltitude clouds, with base heights (indicated from LD-40 data in green) at roughly $5 \mathrm{~km}$, which were eventually replaced with lower clouds with base heights less than $500 \mathrm{~m}$. A nearby radiosonde found the melting layer height of $0^{\circ} \mathrm{C}$ at $570 \mathrm{~m}$, and the homogenous freezing threshold of $-40^{\circ} \mathrm{C}$ at 

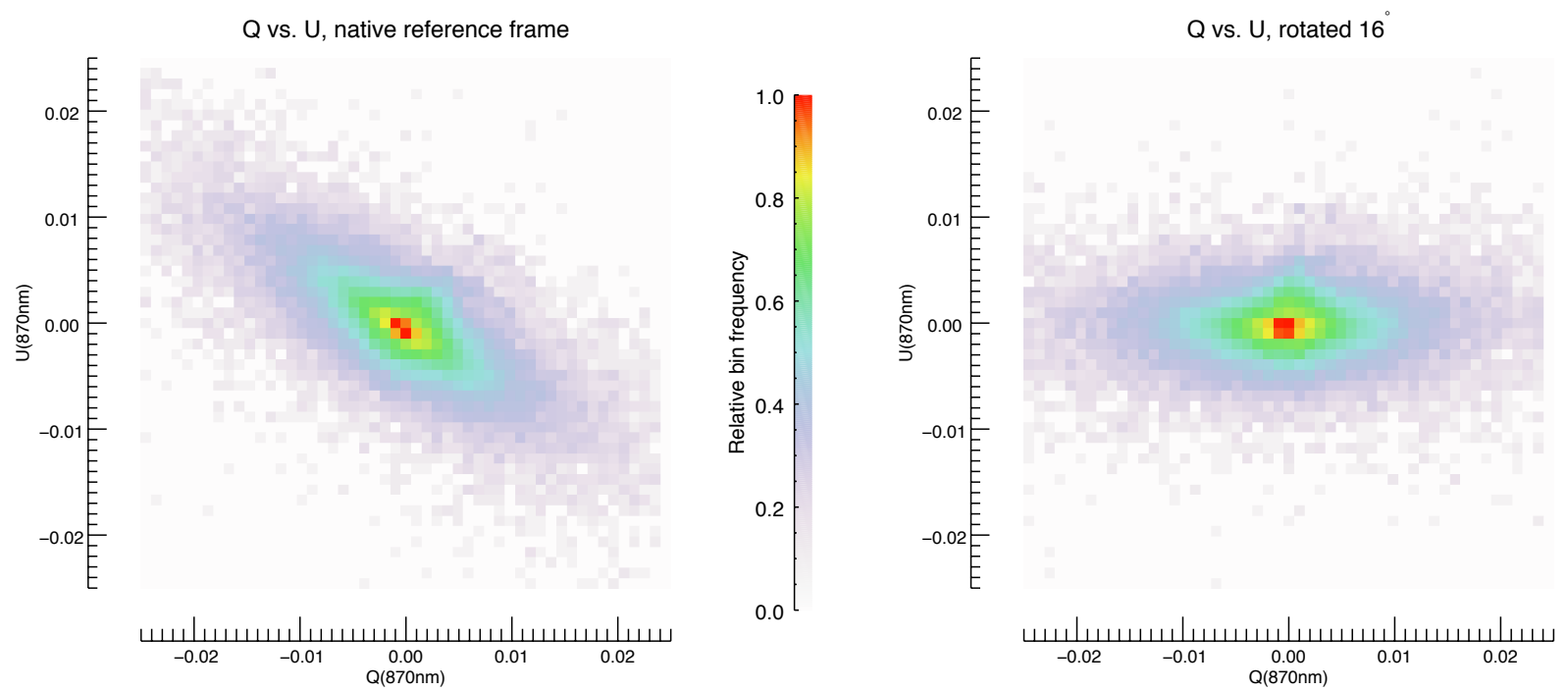

Figure 10. Two-dimensional histograms of $Q$ vs. $U$ for the AERONET Cimel instrument operating at the CESAR site from 9 June 2010 to 15 March 2013. The histogram on the left is for $Q$ and $U$ defined assuming the instrument linear polarizers are aligned with the solar principal plane. Scattering theory for randomly oriented particles indicates that $U$ should be minimized and $Q$ maximized when they are defined with respect to the solar principal plane. Since this is not the case, we found that only by rotating the assumed polarizing filter orientation by $16^{\circ}$ could we pinpoint the appropriate distribution of $Q$ and $U$, shown on the right.

$7.4 \mathrm{~km}$. Therefore, we expect that the higher-altitude clouds were comprised of ice, and the lower clouds of water.

Zenith-viewing Cimel observations at CESAR are shown as the blue, black, and red dots on Fig. 11. Color indicates the expected cloud phase, where $Q>0.0001$ is identified as comprised of liquid phase droplets, and $Q<-0.0001$ as ice. Black points were not identified as either phase. The 0.0001 threshold was chosen based upon measurement uncertainty assessments described in Appendix A. Cimel observations are made in bursts of 10 measurements. As we can see, each burst typically had a wide range of values, which based on threshold alone would indicate both liquid and ice phase clouds. Clouds are unlikely to change at such short temporal and spatial scales, so this scatter indicates measurement uncertainty. In an attempt to reduce this, we averaged each burst of measurements to create a temporally smoothed product, shown by diamonds in Fig. 11. On this day, the smoothed product does seem to indicate cloud thermodynamic phase, identifying the early, high-altitude clouds as ice and the later, lower clouds as liquid. However, one should note that this scene contains complicating factors that were not simulated in our sensitivity study. The results we show in Fig. 4 were computed for a single, plane-parallel, cloud. The scenario presented in Fig. 11 (and later in Fig. 13) represents far more complicated scenes, where multiple cloud layers, 3-D effects, and other cloud heterogeneity could contribute to variability in $Q$. Multiple layers of varying phase would be subject to the phenomena expressed in Fig. 9, where an ice layer on top of a liquid layer pushes the value of $Q$ negative to a degree larger than expected for the actual ice cloud frac- tion. That said, the LD-40 did not find secondary cloud layers above the lowest cloud base, except for a small section around UTC noon. Regardless, success for this complicated scene provides support for the use of $Q$ to determine cloud thermodynamic phase, although a rigorous test would incorporate a much larger data sample.

Observations from the entire data set provide a more comprehensive and quantitative assessment of this thermodynamic phase detection. Figure 12 shows the two-dimensional histograms of observed $Q$ and cloud base height. Although the value of $Q$ depends on cloud optical thickness, ice crystal aspect ratio, crystal roughness, and solar geometry, generally $Q$ is negative for ice clouds. If the observations are similar to the simulations, we would expect to see a negative correlation. This lack of correlation is maintained even for the temporally smoothed data (Fig. 12b), which presumably has less short variability indicative of measurement noise. Seasonal differences within the cloud base height data set were also examined. Using NASA MERRA (Modern-Era Retrospective Analysis for Research and Applications) reanalysis, we found the following for the Netherlands in December: $0{ }^{\circ} \mathrm{C}$ is at roughly $200 \mathrm{~m},-20^{\circ} \mathrm{C}$ is at roughly $4 \mathrm{~km}$, and $-40^{\circ} \mathrm{C}$ is at roughly $7 \mathrm{~km}$; while in July $0^{\circ} \mathrm{C}$ is at roughly $2.5 \mathrm{~km}$, $-20^{\circ} \mathrm{C}$ is at roughly $6 \mathrm{~km}$, and $-40^{\circ} \mathrm{C}$ is at roughly $8.5 \mathrm{~km}$. These numbers indicate that the level above which ice clouds can be expected increases with height and that above $4-6 \mathrm{~km}$ most clouds are expected to be glaciated. Based on these facts, we would expect an increasingly skewed distribution of $Q$ with increasing height. 


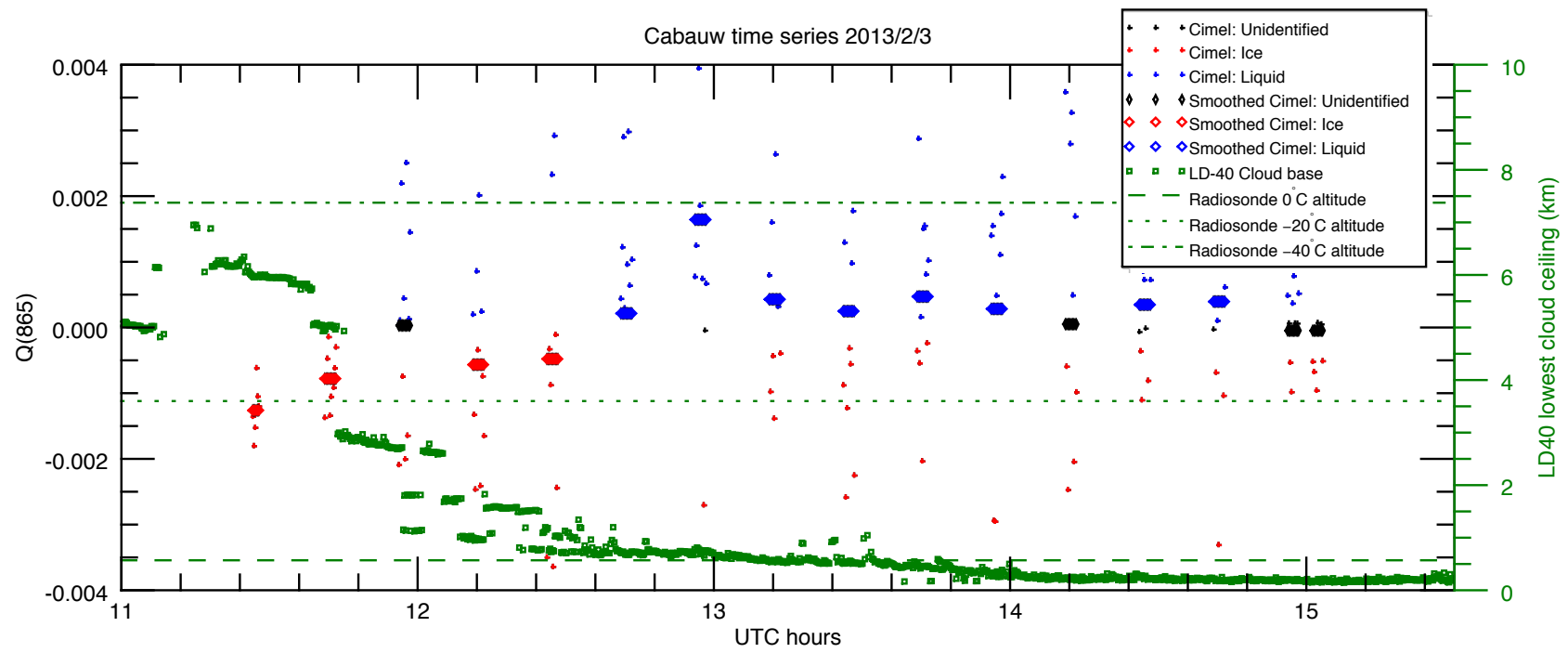

Figure 11. Cimel polarized zenith radiance and Vaisala LD-40 ceilometer data from 3 February 2013, at the CESAR site. Local noon was at 13:00 UTC. Ceilometer data (green) indicate high-altitude (ice) clouds until about 12:00 UTC, when low-altitude (water) clouds appeared. Cimel data (tagged in blue for liquid, red for ice, black otherwise) show little indication of cloud phase. Smoothed data (averages within a 10 min moving window) do a slightly better job of indicating cloud phase and are indicated by blue, red, and black diamonds. A radiosonde launched at the Royal Netherlands Meteorological Institute (EHDB) in De Bilt, roughly $25 \mathrm{~km}$ northeast of CESAR, found temperatures of $0{ }^{\circ} \mathrm{C}$ at $570 \mathrm{~m},-20^{\circ} \mathrm{C}$ at $3600 \mathrm{~m}$, and $-40^{\circ} \mathrm{C}$ at roughly $7.4 \mathrm{~km}$.
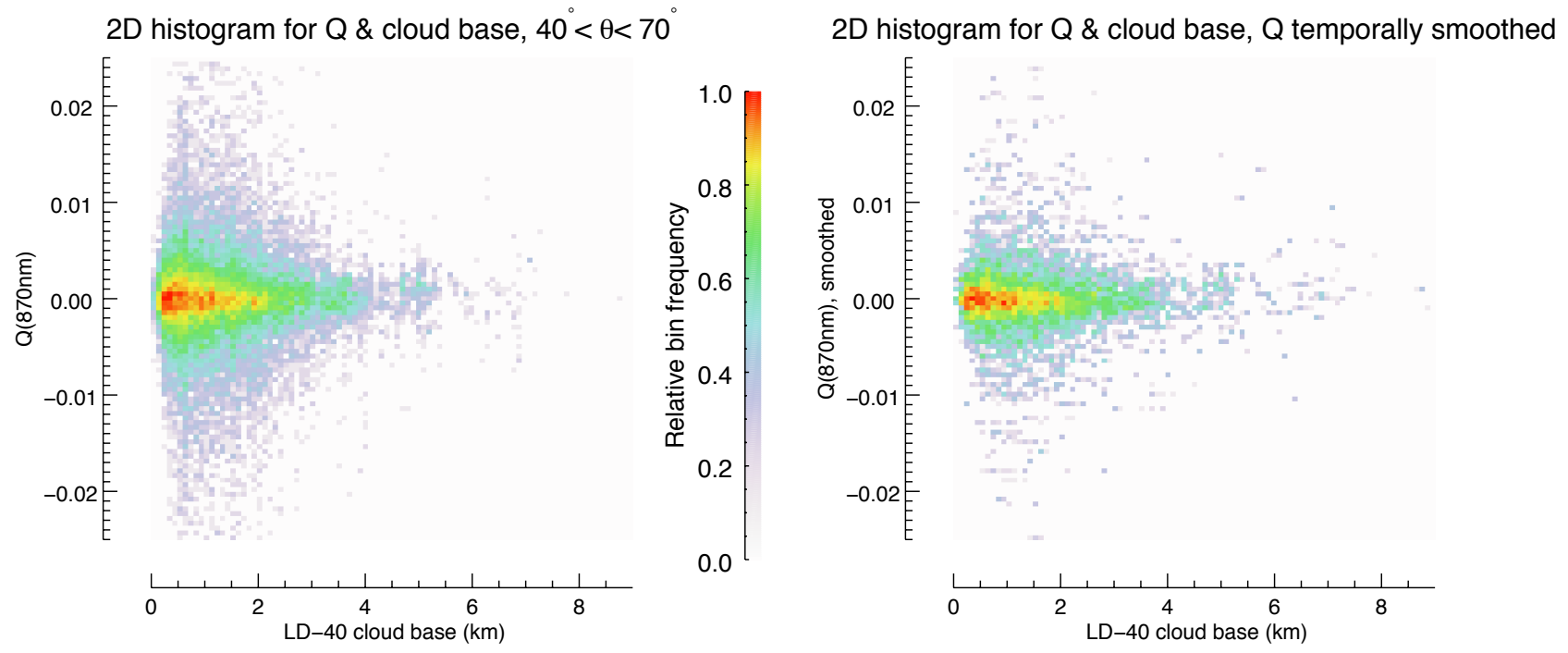

Figure 12. Two-dimensional histograms of the single-channel AERONET $Q$ compared to cloud base height determined by the LD-40 ceilometer at the CESAR site. Original AERONET data are shown on the left, while the values at the right represent temporally smoothed values. To clarify display, $Q$ s with an absolute value less than 0.0001 were removed. For the original data, $50 \%$ were larger than this threshold, while $46 \%$ were less. For the smoothed data, $48 \%$ were larger than this threshold, while $45 \%$ were less. Data were gathered between 9 June 2010 and 28 February 2013.

While disappointing, these results were not entirely unexpected. The Cimel sun photometers were designed to measure the DoLP, not $Q$, and had an unknown amount of measurement uncertainty. While this analysis is also constrained by appropriateness of our cloud thermodynamic phase proxies, the scatter of Cimel $Q$ observations shown in Fig. 11 shows how those measurements are dominated by scatter. Appendix A is an assessment of two types of measurement uncertainty (polarizing filter frame of reference knowledge and polarization efficiency). Presumably, error due to these sources is fixed. Random, highly temporally variable sources of uncertainty are most likely electronic and detector-related, 


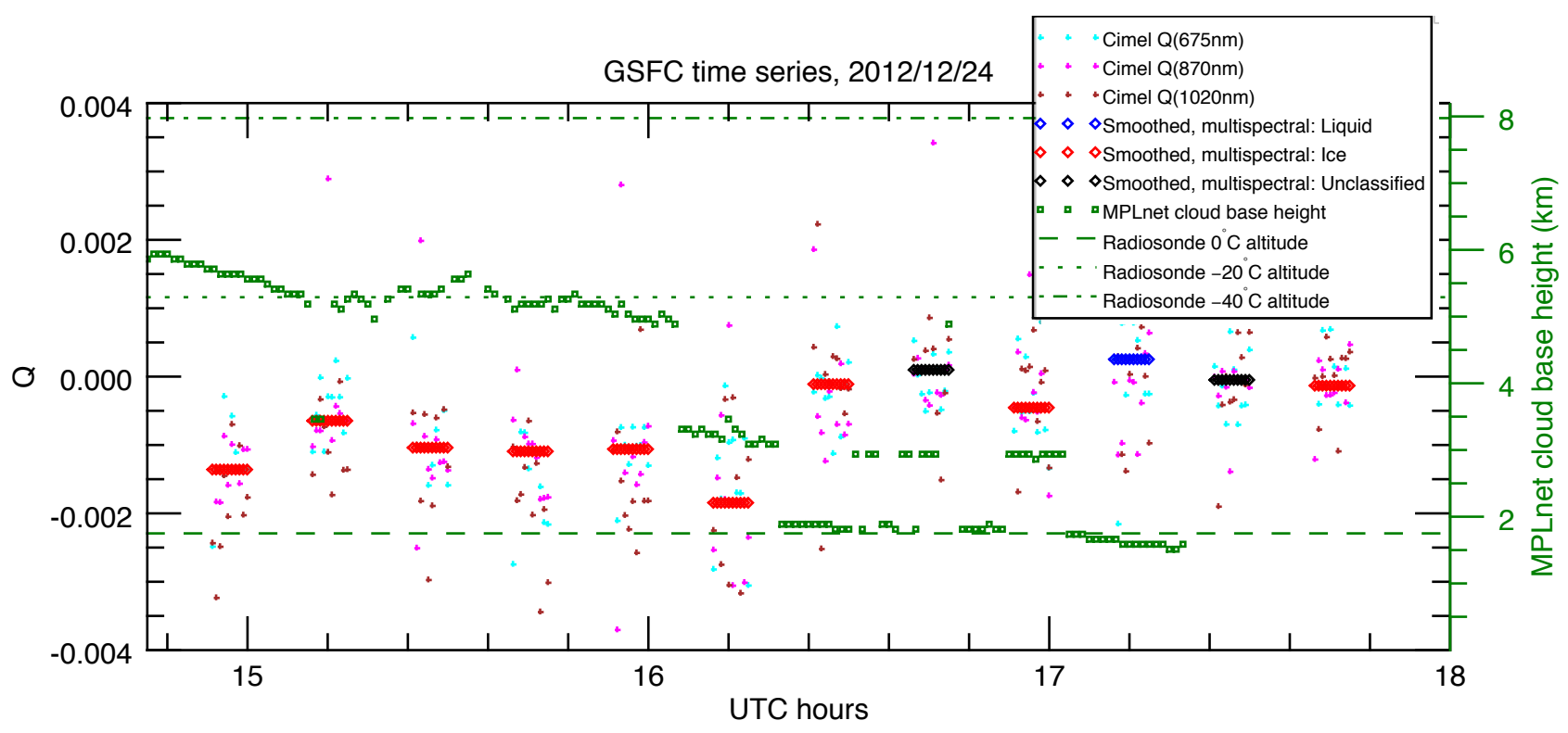

Figure 13. Cimel polarized radiance and MPLNET cloud base height from 24 December 2012 at the NASA GSFC site. Local noon was at 17:00 UTC. Lidar cloud base heights (green) indicate high-altitude clouds before roughly 16:00, followed by low-altitude clouds. Cimel nadir observations of $Q$ at $675 \mathrm{~nm}$ (cyan), $870 \mathrm{~nm}$ (magenta), and $1020 \mathrm{~nm}$ (brown) show a high degree of scatter but generally more negative values during high-altitude cloud cover. A radiosonde launched at Sterling, Virginia (Washington Dulles International Airport), roughly $50 \mathrm{~km}$ west of NASA GSFC, found temperatures of $0^{\circ} \mathrm{C}$ at $1750 \mathrm{~m},-20^{\circ} \mathrm{C}$ at $5.3 \mathrm{~km}$ and $-40^{\circ} \mathrm{C}$ at roughly $8 \mathrm{~km}$, indicating that the lowest clouds were almost certainly comprised of liquid droplets, while the higher clouds were probably comprised of ice particles. A multispectral smoothed product, representing the median of a moving window of data from all three channels taken within 8 min of the window center, is shown as diamonds. These data are classified in the same way as were the CESAR data, where values less than -0.0001 are identified as ice (red), larger than 0.0001 as liquid (blue), and unclassified (black) between those values.

but difficult for us to characterize without more information about the instrument. Because the $Q$ and $U$ elements of the Stokes vector are determined by differences between channels (see Eq. 2), uncertainty due to this type of noise is magnified. Furthermore, we note that the Cimels turn into cloud mode only when the cloud contamination is unambiguous, which may mean that thin cirrus clouds are not included frequently in these measurements.

\subsection{Multiple-channel polarimeter site: NASA GSFC}

The AERONET Cimel instrument that was deployed at CESAR represents an effort, more than a decade old, to determine aerosol properties from Cimels using polarization (e.g., Vermeulen et al., 2000). These instruments used DoLP and a single channel $(870 \mathrm{~nm})$ to find aerosol properties using both direct solar and sky radiance measurements. More recently, Cimels have been developed that have multiple channels. These have been used to retrieve aerosol optical properties with DoLP (Li et al., 2004, 2006, 2007, 2009, 2010, 2013). A portion of these instruments also make zenith mode measurements in the cloud mode, although polarization data from these measurements are not currently utilized. We assessed a subset of these data acquired at NASA GSFC in Greenbelt, Maryland. Figures 13 and 14 illustrate the results of this test, which shows more promise than data collected at the CESAR site (Sect. 3.1). In this case, we used cloud base height from a coincident micropulse lidar (Micro-Pulse Lidar Network, or MPLNET) (Welton et al., 2001) and temporally smoothed the Cimel data. Since multiple instrument channels were observing polarization, we used the three closest to $870 \mathrm{~nm}$ to generate a "multi-spectral" product, where positive of $Q$ values indicate liquid, and negative values indicate ice. The 675 , 870 , and $1020 \mathrm{~nm}$ channels were chosen for this product because of the similarity of the way they express polarimetric cloud scattering (as shown by our simulations; see Fig. 7). Our intent was to reduce random noise by "smoothing" the data, created from the median value of a moving window of all (multispectral) data within an 8 min window.

An example of these data is shown in Fig. 13, which is a case similar to Fig. 11, where high-altitude clouds earlier in the day (24 December 2012) were later obscured by lower clouds. $Q$ is lower for the high-altitude (and most likely ice) clouds than it is for low-altitude (probably liquid) clouds. Data from individual spectral channels show large amounts of scatter within short time windows, indicating that $Q$ from these instruments contains large (for our purposes) quantities of random noise. In an attempt to reduce this noise, we "smoothed" the combined 675,870 , and $1020 \mathrm{~nm}$ data to create the product shown as diamonds in Fig. 13. Like before, 

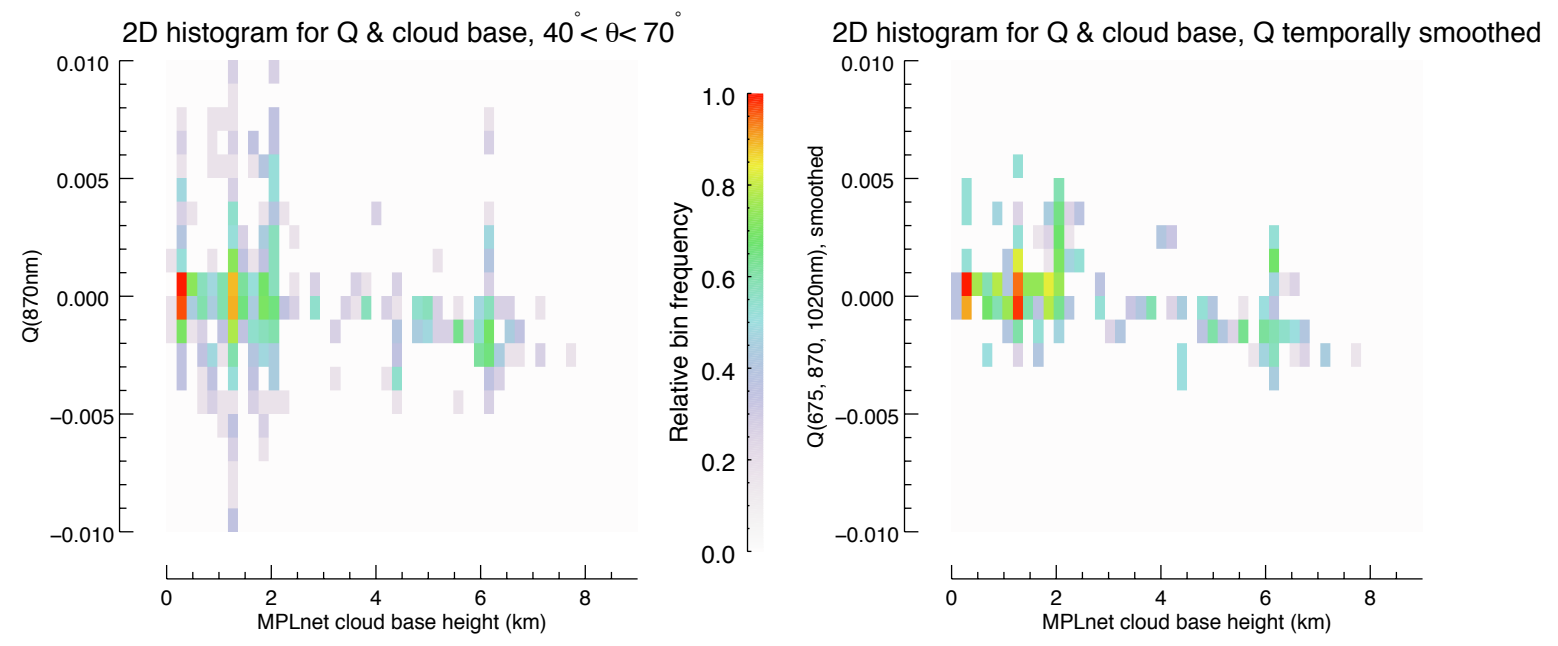

Figure 14. Two-dimensional histograms of $Q(870 \mathrm{~nm})$ with respect to MPLNET cloud base height (left) and the smoothed multispectral $(675,870$, and $102 \mathrm{~nm}) Q$ product versus the same (right) with the multi-wavelength Cimel instrument at NASA GSFC, for December 2012. The apparent inverse relationship between $Q$ and cloud base height is consistent with the simulations in Sect. 2 .

we classified this product so that values less than -0.0001 are identified as ice, and those greater than 0.0001 as liquid. We can see that what we expect to be ice is indeed identified that way, but liquid clouds are not always properly identified. The smoothed product does have $Q$ values that are larger for liquid than ice clouds, but not large enough to be consistently classified correctly. This points to the possibility of systematic biases in $Q$, in addition to the random noise the multispectral product is intended to reduce. Indeed, our uncertainty analysis in Appendix A indicates that uncertainty in reference frame knowledge (which we determined with $U$ as shown in Fig. 10) can be important.

Figure 14 is a two-dimensional histogram of all data from the month of December 2012 in Greenbelt, and it represents a more complete analysis than the single day described in Fig. 13. The negative relationship is also expressed here. If we choose $3 \mathrm{~km}$ as a threshold between water and ice clouds, we can use the $Q$ multi-spectral product to correctly identify liquid clouds $78 \%$ of the time, and correctly identify ice clouds $76 \%$ of the time. While this result is promising, it requires further evaluation at more sites and solar geometries, as well as additional information from, e.g., ground-based radar to provide better independent estimates of cloud thermodynamic phase (such as in Shupe, 2007).

\section{Discussion}

Our simulations show that the direction of linear polarization (as expressed by the sign of the $Q$ element of the Stokes polarization vector defined in the solar scattering plane) indicates cloud thermodynamic phase in most situations when clouds are observed with passive instruments from below. Liquid phase cloud droplets have positive values of $Q$, in- dicating that the linear polarization is perpendicular to the scattering plane, while ice phase cloud particles have negative $Q$, meaning that their polarization is parallel to the scattering plane.

These conclusions were reached with an atmospheric multiple-scattering radiative transfer model, which performed these simulations for a variety of ice particle shapes and several liquid droplet size distributions. We found that the amount of linear polarization (for either liquid or ice) is largest for optically thin clouds and decreases to nothing for optical depths larger than 10 or 15 . Geometries where the scattering angle between the incoming solar path and the observation direction are between 40 and $70^{\circ}$ are optimal for thermodynamic phase discrimination. Cloud droplet size distribution has a weak influence on the amount of polarization, but ice particles with an extreme AR tend to polarize most, and are therefore easiest to distinguish from liquid clouds. Spectral channels with sensitivity in the red or near-infrared are also best for these purposes since liquid droplets polarize strongest at those wavelengths. Finally, while these properties are relatively insensitive to cloud base height or ground surface reflectance, the ability to distinguish ice from liquid clouds diminishes at scattering angles less than $20^{\circ}$. This is also the case if the geometry is such that a halo produced by scattering from pristine ice crystals is observed.

An existing network of ground-based sun photometers and radiometers (AERONET; Holben et al., 1998) makes regular observations of clouds (Marshak et al., 2000; Barker and Marshak, 2001; Marshak et al., 2004; Chiu et al., 2006, 2010). A subset of these instruments have polarization sensitivity that is used to determine aerosol optical properties (Li et al., 2004, 2006, 2007, 2009, 2010, 2013) but not employed for cloud property retrieval. Our simulations indicate that these data could also be utilized to determine cloud ther- 
modynamic phase, at least for situations where the cloud optical depth is small and geometry is appropriate. This could be an alternate (or complementary) means to determine cloud thermodynamic phase to techniques that use passive infrared observation (e.g., Turner et al., 2003), spectral techniques (e.g., LeBlanc et al., 2014), or active observation of cloud depolarization with lidars and radars (e.g., Sassen, 1991; Zrnic and Ryzhkov, 1999). Complimentary techniques would be especially useful for techniques that have less accuracy for low cloud optical depths, since the polarization-based approach is most accurate for optically thin clouds. Furthermore, this technique can improve cloud optical depth retrievals that use total (unpolarized) radiation by constraining the retrieval lookup table to the appropriate cloud phase (Chiu et al., 2010).

Successful cloud thermodynamic phase determination depends not just on scene conditions, but on instrument capability as well. Specifically, the accuracy with which $Q$ is determined is key, especially as cloud optical depth increases. For AERONET, calibration methodologies and uncertainty estimates exist for the magnitude of polarization (DoLP), but not for the direction of polarization $(Q)$. It was therefore difficult to know the utility of these techniques without an investigation of AERONET data collected alongside other means of assessing cloud phase, such as by cloud base height.

We tested the ability of polarized AERONET Cimel instruments to determine cloud phase with data from two different sites and with two versions of the polarized Cimel instrument. First, we used data from the CESAR site in the Netherlands. The AERONET Cimel instrument at that site is an older version that is sensitive to polarization at a single channel $(870 \mathrm{~nm})$. The first hurdle in analyzing this data was determining the geometrical reference frame for the Stokes polarization vector (Eq. 2). Typically, the polarization from Cimel instruments is represented by the DoLP, which expresses amount of linear polarization and does not have a reference frame. For our purposes, however, we need to know the Stokes vector reference frame, which we determined by minimizing the $U$ vector element. Once we did this, we found a high degree of what appeared to be random noise, which we reduced by smoothing the data within an 8 min window. While this did make it possible to find days where AERONET observations correspond with information about cloud base height (Fig. 11), we were unable to find a systematic relationship between cloud base height and $Q$ (Fig. 12). We performed a similar analysis with data from an AERONET Cimel at GSFC. This instrument is a newer variety that has polarization sensitivity in all channels. Like the instrument at CESAR, we found the polarization reference frame with $U$, and smoothed the data within an 8 min window. We were able to find a weak relationship between cloud base height and $Q$ (Fig. 14), possibly because we had more data within our $8 \mathrm{~min}$ smoothing window due to the use of three channels. As we have shown with a single-day time series (Fig. 13), however, noise and apparent biases still exist.
These results do not indicate with certainty if it is possible to use AERONET Cimel instruments to reliably determine cloud thermodynamic phase. Several steps could be performed to improve the ability of these instruments to determine $Q$ and $U$, and better characterize their uncertainty. These include

1. improving the understanding of the exact instrument geometry while making a polarized cloud measurement, which would provide a means to determine the polarization frame of reference without the use of $U$.

2. characterization of the uncertainty associated with filter orientation and measurement geometry (as we have shown in our uncertainty assessment in Appendix A, knowledge of the reference frame and filter orientation to an uncertainty of tenths of a degree are required to provide an uncertainty less than the threshold of $10^{-4}$ that we used to discriminate between liquid and ice clouds);

3. characterization of overall Cimel uncertainty for $Q$ and $U$, possibly using a modification of the methods described in Li et al. (2010);

4. modification of the measurement protocol so that clouds are not observed at zenith, but in the solar principal plane at a scattering angle angle of roughly $55^{\circ}$;

5. modification of the measurement protocol to increase signal to noise and reduce random uncertainty, by using longer integration times or by making bursts of measurements (although it should be noted for this and the previous item that any modification to measurement protocol within AERONET is a complex task).

As part of these efforts, we have purchased a polarizationsensitive Cimel instrument to be installed at our home institution, NASA Ames Research Center, at Moffett Field, California. This instrument will be incorporated into AERONET and also used to address some of the items on the list above. Additionally, we are constructing a simple linearpolarization-sensitive instrument for the investigation of this technique, called the Sky Polarization Radiometric Instrument for Test and Evaluation (SPRITE). The instrument, shown under construction in Fig. 15, utilizes high-resolution (24 bit) single-channel microradiometers designed for ocean optical remote sensing instruments such as the Optical Sensors for Planetary Radiant Energy (OSPREy; Hooker et al., 2012) and the Compact-Optical Profiling System (C-OPS, Morrow et al., 2010). The; microradiometers are manufactured by Biospherical Instruments, Inc. and were chosen for their high resolution, compact and modular profile, and low cost. The initial instrument configuration will have a polarization-sensitive channel near $870 \mathrm{~nm}$ (using three sensors) and a single, non-polarization-sensitive channel at or near $440 \mathrm{~nm}$, so that cloud mode observations as in Chiu et al. 
(2010) can be replicated. If precise calibration and low uncertainty are indeed possible, more channels, and more sophisticated housing, can be added, and the lessons learned can be applied to other instrumentation.

\section{Conclusions}

When observed from below, cloud thermodynamic phase of clouds is expressed in the direction of linear polarization, although the magnitude (and thus detection) of that polarization is inversely proportional to cloud optical depth. We performed radiative transfer simulations that show this is the case and tested the range of conditions under which it is most clear. We then investigated polarimetric observations of clouds from the ground and compared the polarization direction to other indicators of cloud thermodynamic phase to see if our simulations could be confirmed. We did so with data from AERONET, a network of ground-based sun photometers and radiometers, a portion of which have polarization sensitivity. We found a large amount of noise and apparent uncertainty in these data, at least for the determination of polarization direction. This was to be expected, since these instruments were primarily designed to produce measurements of the magnitude of polarization, and it is these data that are utilized in retrieval algorithms. We tested instruments with a single (NIR) polarization-sensitive channel and could not find a systematic relationship between polarization direction and cloud base height (our proxy for thermodynamic phase), but we did find a weak relationship with an instrument that has multiple polarization-sensitive channels. These results do not conclusively indicate if AERONET instruments can be used to determine cloud thermodynamic phase. We describe a set of recommendations for further activities that will clarify this ambiguity, including a complete characterization and uncertainty analysis of polarimetric direction measurements (see Appendix A), modification of AERONET measurement protocol, and investigation with a prototype instrument expressly designed to identify the limits of polarimetric accuracy and capability.

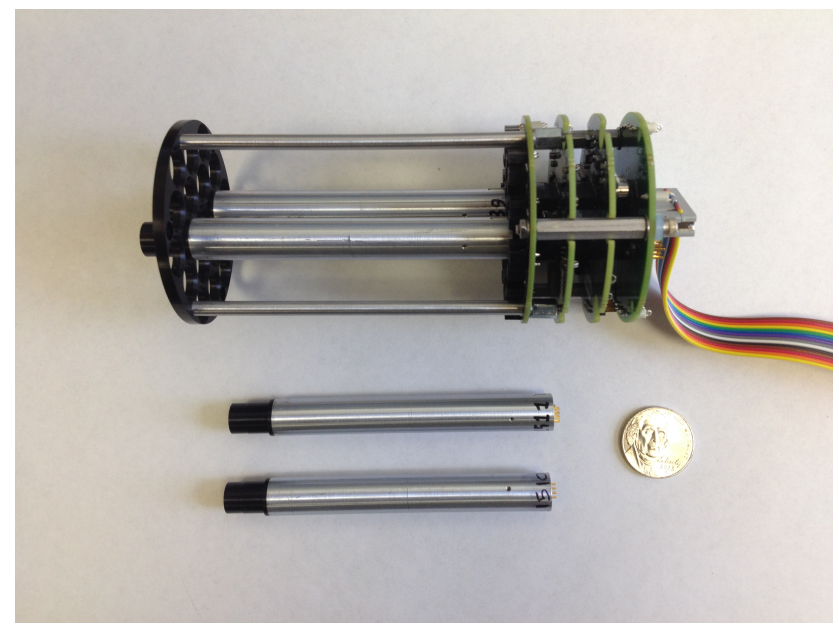

Figure 15. SPRITE, a prototype instrument for the investigation of the polarimetric cloud thermodynamic phase determination technique. Microradiometers manufactured by Biospherical Instruments, Inc. (below) will be used with a modular housing (above) that allows for up to 19 individual microradiometers. 


\section{Appendix A: Uncertainty for instruments with linear polarizers}

This appendix describes the measurement systematic uncertainty due to polarizing filter placement and throughput. We limit ourselves to these polarization-specific sources of uncertainty and defer to the far more detailed investigations in publications such as Torres et al. (2014) and Li et al. (2010) for other sources of uncertainty.

Both the AERONET Cimel radiometer and the test instrument we have in development use combinations of linearly polarizing filters to determine the Stokes vector. Chandrasekhar's equation for linearly polarized radiation (Chandrasekhar, 1960, Eq. 163) describes the observed signal, $\hat{I}(X)$, for a detector with a linear polarizer oriented at $X^{\circ}$ from the Stokes vector reference plane:

$\hat{I}(X)=\frac{1}{2}[I+Q \cos 2 X+U \sin 2 X]$,

where $I, Q$, and $U$ are Stokes vector elements. From this, we can derive Eq. (2) for the AERONET Cimel filter configuration:

$\boldsymbol{I}=\left[\begin{array}{c}I \\ Q \\ U\end{array}\right]=\left[\begin{array}{c}\frac{2}{3}\left(\hat{I}\left(0^{\circ}\right)+\hat{I}\left(120^{\circ}\right)+\hat{I}\left(240^{\circ}\right)\right) \\ \frac{2}{3}\left(2 \hat{I}\left(0^{\circ}\right)-\hat{I}\left(120^{\circ}\right)-\hat{I}\left(240^{\circ}\right)\right) \\ \frac{2}{\sqrt{3}}\left(\hat{I}\left(240^{\circ}\right)-\hat{I}\left(120^{\circ}\right)\right)\end{array}\right]$.

If we include an uncertainty in the placement and knowledge $e$, in Eq. (A1), we have

$$
\begin{aligned}
\hat{I}(X+e)= & \frac{1}{2}[I+Q(\cos 2 x \cos 2 e-\sin 2 X \cos 2 e) \\
& +U(\sin 2 X \cos 2 e+\cos 2 X \sin 2 e)] .
\end{aligned}
$$

For a sensor with a polarizing filter aligned to the reference plane $\left(X=0^{\circ}\right)$, the difference between expected and observed signal is

$$
\begin{aligned}
\sigma_{e 0} & =|\hat{I}(0+e)-\hat{I}(0)| \\
& =\left|\frac{1}{2}(Q \cos 2 e-Q+U \sin 2 e)\right| .
\end{aligned}
$$

For the channels with polarizing filters at other orientations, we have

$$
\begin{aligned}
\sigma_{e 120}= & \mid \frac{1}{4}(Q[1-\cos 2 e+\sqrt{3} \sin 2 e] \\
& +U[\sqrt{3}-\sqrt{3} \cos 2 e-\sin 2 e]) \mid
\end{aligned}
$$

and

$$
\begin{aligned}
\sigma_{e 240}= & \mid \frac{1}{4}(Q[1-\cos 2 e-\sqrt{3} \sin 2 e] \\
& +U[-\sqrt{3}+\sqrt{3} \cos 2 e-\sin 2 e]) \mid .
\end{aligned}
$$

Additionally, we define $f$ as a fixed, linear uncertainty associated with the efficiency of the polarizing filters. It is identical for each channel, so that $\sigma_{\mathrm{f} 0}=\sigma_{\mathrm{f} 120}=\sigma_{\mathrm{f} 240}=f$.

To determine uncertainty in terms of Stokes vector elements $-I, Q$, and $U$ - we compute the partial derivatives of Eq. (A2):

$\frac{\partial I}{\partial \hat{I}\left(0^{\circ}\right)}=\frac{2}{3}, \quad \frac{\partial I}{\partial \hat{I}\left(120^{\circ}\right)}=\frac{2}{3}, \quad \frac{\partial I}{\partial \hat{I}\left(240^{\circ}\right)}=\frac{2}{3}$

$\frac{\partial Q}{\partial \hat{I}\left(0^{\circ}\right)}=\frac{4}{3}, \quad \frac{\partial Q}{\partial \hat{I}\left(120^{\circ}\right)}=\frac{-2}{3}, \quad \frac{\partial Q}{\partial \hat{I}\left(240^{\circ}\right)}=\frac{-2}{3}$

$\frac{\partial U}{\partial \hat{I}\left(0^{\circ}\right)}=0, \quad \frac{\partial U}{\partial \hat{I}\left(120^{\circ}\right)}=\frac{2}{\sqrt{3}}, \quad \frac{\partial U}{\partial \hat{I}\left(240^{\circ}\right)}=\frac{2}{\sqrt{3}}$.

Using linear error propagation rules, assuming no correlation between $e$ and $f$, we can write the uncertainty in terms of the individual Stokes vector elements:

$$
\begin{aligned}
\sigma_{I}^{2} & =\frac{4}{9}\left(\sigma_{e 0}^{2}+\sigma_{e 120}^{2}+\sigma_{e 240}^{2}+3 f^{2}\right) \\
\sigma_{Q}^{2} & =\frac{4}{9}\left(4 \sigma_{e 0}^{2}+\sigma_{e 120}^{2}+\sigma_{e 240}^{2}+6 f^{2}\right) \\
\sigma_{U}^{2} & =\frac{4}{3}\left(\sigma_{e 120}^{2}+\sigma_{e 240}^{2}+2 f^{2}\right) .
\end{aligned}
$$

For the $I$ element of the Stokes vector, this expands to

$$
\begin{aligned}
\sigma_{I}^{2}= & \frac{4}{3} f^{2}+\frac{1}{9}|Q \cos 2 e-Q+U \sin 2 e|^{2} \\
& +\frac{1}{36} \mid Q[1-\cos 2 e+\sqrt{3} \sin 2 e] \\
& +\left.U[\sqrt{3}-\sqrt{3} \cos 2 e-\sin 2 e]\right|^{2} \\
& +\frac{1}{36} \mid Q[1-\cos 2 e-\sqrt{3} \sin 2 e] \\
& +\left.U[-\sqrt{3}+\sqrt{3} \cos 2 e-\sin 2 e]\right|^{2},
\end{aligned}
$$

which converges to $\frac{4}{3} f^{2}$ as $e$ becomes small, or if there is no polarization $(Q=U=0)$. 


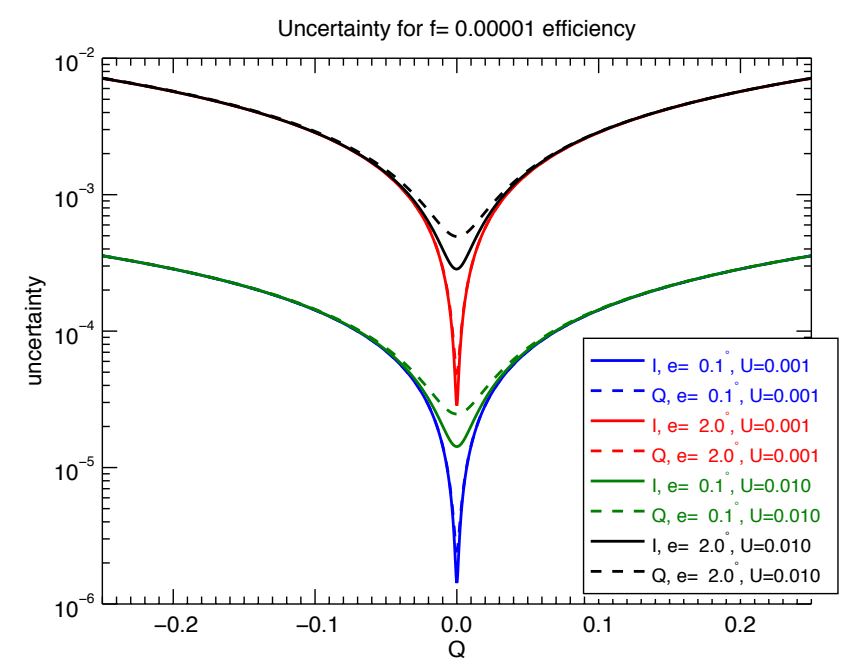

Figure A1. Polarimetric uncertainty in reflectance units for a scene with $I=0.5, \theta_{\mathrm{S}}=45^{\circ}$, and $f=10^{-5}$, and various values of $Q, U$, and $e$.

For the $Q$ Stokes vector element, this is

$$
\begin{aligned}
\sigma_{Q}^{2}= & \frac{8}{3} f^{2}+\frac{4}{9}|Q \cos 2 e-Q+U \sin 2 e|^{2} \\
& +\frac{1}{36} \mid Q[1-\cos 2 e+\sqrt{3} \sin 2 e] \\
& +\left.U[\sqrt{3}-\sqrt{3} \cos 2 e-\sin 2 e]\right|^{2} \\
& +\frac{1}{36} \mid Q[1-\cos 2 e-\sqrt{3} \sin 2 e] \\
& +\left.U[-\sqrt{3}+\sqrt{3} \cos 2 e-\sin 2 e]\right|^{2},
\end{aligned}
$$

which converges to $\frac{8}{3} f^{2}$ as $e$ becomes small, or if there is no polarization $(Q=U=0)$. This is nearly identical to Eq. (A9), except the first and second term on the right-hand side are 2 and 4 times larger. Since $I^{2} \geq Q^{2}+U^{2}+V^{2}$, we can expect $\frac{\sigma_{Q}^{2}}{Q^{2}} \geq \frac{\sigma_{I}^{2}}{I^{2}}$; i.e., the relative error of $Q$ will always be equal to or larger than that of $I$.
For the $U$ Stokes vector element, the uncertainty is

$$
\begin{aligned}
\sigma_{U}^{2}= & \frac{8}{3} f^{2}+\frac{1}{12} \mid Q[1-\cos 2 e+\sqrt{3} \sin 2 e] \\
& +\left.U[\sqrt{3}-\sqrt{3} \cos 2 e-\sin 2 e]\right|^{2} \\
& +\frac{1}{12} \mid Q[1-\cos 2 e-\sqrt{3} \sin 2 e] \\
& +\left.U[-\sqrt{3}+\sqrt{3} \cos 2 e-\sin 2 e]\right|^{2},
\end{aligned}
$$

which converges to $\frac{8}{3} f^{2}$ as $e$ becomes small, or if there is no polarization $(Q=U=0)$.

Figure A1 expresses the polarimetric uncertainty graphically. As we can see, linear polarizer placement knowledge (e) is important. An uncertainty of $e=2^{\circ}$ (black and red) would create uncertainties in $I$ and $Q$ nearly as significant as the results shown in Fig. 4. An uncertainty of $e=0.1^{\circ}$ (blue and green) would be more acceptable. The uncertainty estimates in $\mathrm{Li}$ et al. (2014), who assume $e=1^{\circ}$ but $f=0$, are roughly between our $e=0.1^{\circ}$ and $e=2^{\circ}$ results. The uncertainties in $I$ and $Q$ are nearly identical and differ only for small values of $Q$ when $U$ is not negligible. Although it is not shown in this figure, it should also be noted that the uncertainty in $f$ does not become relevant until it approaches $f \geq 0.01$. Single-channel Cimel observations indicate that there is what appears to be noise on the order of $10^{-3}$ at the CESAR site (see Figs. 11 and 12). Presumably, $e$ and $f$ are systematic uncertainties that would not be expressed as part of this noise, but we mention this to illustrate the general importance of these uncertainty estimates. It would appear that the relative noise contribution to overall uncertainty is large. Assuming a $\sqrt{n}$ uncertainty reduction when averaging, reducing noise from $10^{-3}$ to $10^{-4}$ would require averages of 100 measurements. 
Acknowledgements. This research was supported by Science Innovation Fund (SIF) grants at NASA Ames Research Center (K. Knobelspiesse, S. Dunagan, B. van Diedenhoven) and NASA Goddard Space Flight Center (A. Marshak, B. Holben). Thanks to to John Livingston for his help finding validation data and to members of the NASA Ames Sunphotometer-Satellite Team for informally reviewing this manuscript. LD-40 data from the CESAR site, and radiosonde data from De Bilt, are provided courtesy of the Koninklijk Nederlands Meteorologisch Instituut (KNMI). Radiosonde data from Sterling, Virginia, are from the National Weather Service. We thank the members of the AERONET team at the NASA Goddard Space Flight Center for providing instrument calibration, data processing, and field measurement support. The NASA MPLNET is funded by the NASA Earth Observing System and Radiation Sciences Program. We thank the MPLNET PI Judd Welton and MPLNET on-site staff member Sebastian Stewart for their efforts in establishing and maintaining the Goddard Space Flight Center site.

Edited by: M. Wendisch

\section{References}

Auer Jr., A. H. and Veal, D. L.: The dimension of ice crystals in natural clouds, J. Atmos. Sci., 27, 919-926, 1970.

Baran, A. J.: A review of the light scattering properties of cirrus, J. Quant. Spectrosc. Ra., 110, 1239-1260, 2009.

Barker, H. W. and Marshak, A.: Inferring optical depth of broken clouds above green vegetation using surface solar radiometric measurements, J. Atmos. Sci., 58, 2989-3006, 2001.

Bi, L., Yang, P., Liu, C., Yi, B., Baum, B. A., van Diedenhoven, B., and Iwabuchi, H.: Assessment of the accuracy of the conventional ray-tracing technique: Implications in remote sensing and radiative transfer involving ice clouds, J. Quant. Spectrosc. Ra., 146, 158-174, http://www.sciencedirect.com/science/article/pii/ S0022407314001332, 2014.

Campos, E. F., Ware, R., Joe, P., and Hudak, D.: Monitoring water phase dynamics in winter clouds, Atmos. Res., 147, 86-100, 2014

Chandrasekhar, S.: Radiative Transfer, Dover Publications, Inc., New York, NY, USA, 1960.

Chiu, J. C., Marshak, A., Knyazikhin, Y., Wiscombe, W. J., Barker, H. W., Barnard, J. C., and Luo, Y.: Remote sensing of cloud properties using ground-based measurements of zenith radiance, J. Geophys. Res.-Atmos., 111, D16201, doi:10.1029/2005JD006843, 2006.

Chiu, J. C., Huang, C.-H., Marshak, A., Slutsker, I., Giles, D. M., Holben, B. N., Knyazikhin, Y., and Wiscombe, W. J.: Cloud optical depth retrievals from the Aerosol Robotic Network (AERONET) cloud mode observations, J. Geophys. Res., 115, D14202, doi:10.1029/2009JD013121, 2010.

Davis, A. B. and Marshak, A.: Space-time characteristics of light transmitted through dense clouds: A Green's function analysis, J. Atmos. Sci., 59, 2713-2727, 2002.

de Haan, J., Bosma, P., and Hovenier, J.: The adding method for multiple scattering calculations of polarized light, Astron. Astrophys., 183, 371-391, 1987.
Hansen, J. and Travis, L.: Light scattering in planetary atmospheres, Space Sci. Rev., 16, 527-610., 1974.

Hogan, R. J., Illingworth, A., O'Connor, E., and Baptista, J.: Characteristics of mixed-phase clouds. II: A climatology from ground-based lidar, Q.. J. Roy. Meteor. Soc., 129, 2117-2134, 2003.

Holben, B., Kaufman, Y., Eck, T., Slutsker, I., Tanre, D., Buis, J., Setzer, A., Vermote, E., and Reagan, J.: AERONET - A Federated Instrument Network and Data Archive for Aerosol Characterization, Remote Sens. Environ., 66, 1-16, 1998.

Hooker, S., Benhard, G., Morrow, J., Booth, C., Comer, T., Lind, R., and Quang, V.: Optical Sensors for Planetary Radiant Energy (OSPREy): Calibration and Validation of Current and NextGeneration NASA Missions, Tech. Rep. TM-2012-215872, National Aeronautics and Space Administration, 2012.

IPCC: Climate Change 2013 - The Physical Science Basis : Contribution of the Working Group I to the Fifth Assessment Report of the IPCC, Cambridge University Press, New York, NY, USA, 2013.

Kawata, Y.: Circular polarization of sunlight reflected by planetary atmospheres, Icarus, 33, 217-232, 1978.

Knobelspiesse, K., Cairns, B., Schaaf, C., Schmid, B., and Román, M.: Surface BRDF estimation from an aircraft compared to MODIS and ground estimates at the Southern Great Plains site, J. Geophys. Res., 113, 1-21, 2008.

LeBlanc, S. E., Pilewskie, P., Schmidt, K. S., and Coddington, O.: A generalized method for discriminating thermodynamic phase and retrieving cloud optical thickness and effective radius using transmitted shortwave radiance spectra, Atmos. Meas. Tech. Discuss., 7, 5293-5346, doi:10.5194/amtd-7-5293-2014, 2014.

Li, L., Li, Z., Li, K., Blarel, L., and Wendisch, M.: A method to calculate Stokes parameters and angle of polarization of skylight from polarized CIMEL sun/sky radiometers, J. Quant. Spectrosc. Ra., 149, 334-346, 2014.

Li, Z., Goloub, P., Devaux, C., Gu, X., Qiao, Y., Zhao, F., and Chen, H.: Aerosol polarized phase function and single-scattering albedo retrieved from ground-based measurements, Atmos. Res., 71, 233-241, 2004.

Li, Z., Goloub, P., Devaux, C., Gu, X., Deuze, J.-L., Qiao, Y., and Zhao, F.: Retrieval of aerosol optical and physical properties from ground-based spectral, multi-angular, and polarized sunphotometer measurements, Remote Sens. Environ., 101, 519533, 2006

Li, Z., Goloub, P., Blarel, L., Damiri, B., Podvin, T., and Jankowiak, I.: Dust optical properties retrieved from ground-based polarimetric measurements, Appl. Opt., 46, 1548-1553, 2007.

Li, Z., Goloub, P., Dubovik, O., Blarel, L., Zhang, W., Podvin, T., Sinyuk, A., Sorokin, M., Chen, H., Holben, B., Tanré, D., Canini, M., and Buis, J.-P.: Improvements for ground-based remote sensing of atmospheric aerosol properties by additional polarimetric measurements, J. Quant. Spectrosc. Ra., 110, 1954-1961, 2009.

Li, Z., Blarel, L., Podvin, T., Goloub, P., and Chen, L.: Calibration of the degree of linear polarization measurement of polarized radiometer using solar light, Appl. Opt., 49, 1249-1256, 2010.

Li, Z., Gu, X., Wang, L., Li, D., Xie, Y., Li, K., Dubovik, O., Schuster, G., Goloub, P., Zhang, Y., Li, L., Ma, Y., and Xu, H.: Aerosol physical and chemical properties retrieved from ground-based remote sensing measurements during heavy haze days in Beijing 
winter, Atmos. Chem. Phys., 13, 10171-10183, doi:10.5194/acp13-10171-2013, 2013.

Macke, A., Mueller, J., and Raschke, E.: Single scattering properties of atmospheric ice crystals, J. Atmos. Sci., 53, 2813-2825, 1996.

Magee, N. B., Miller, A., Amaral, M., and Cumiskey, A.: Mesoscopic surface roughness of ice crystals pervasive across a wide range of ice crystal conditions, Atmos. Chem. Phys., 14, 1235712371, doi:10.5194/acp-14-12357-2014, 2014.

Marshak, A., Knyazikhin, Y., Davis, A., Wiscombe, W., and Pilewskie, P.: Cloud-vegetation interaction: Use of normalized difference cloud index for estimation of cloud optical thickness, Geophys. Res. Lett., 27, 1695-1698, 2000.

Marshak, A., Knyazikhin, Y., Evans, K., and Wiscombe, W.: The "RED versus NIR" plane to retrieve broken-cloud optical depth from ground-based measurements, J. Atmos. Sci., 61, 19111925, 2004.

Martins, J. V., Marshak, A., Remer, L. A., Rosenfeld, D., Kaufman, Y. J., Fernandez-Borda, R., Koren, I., Correia, A. L., Zubko, V., and Artaxo, P.: Remote sensing the vertical profile of cloud droplet effective radius, thermodynamic phase, and temperature, Atmos. Chem. Phys., 11, 9485-9501, doi:10.5194/acp-11-94852011, 2011.

Morrow, J., Hooker, S., Booth, C., Bernhard, G., Lind, R., and Brown, J.: Advances in Measuring the Apparent Optical Properties (AOPs) of Optically Complex Waters, Tech. Rep. TM-2010215856, National Aeronautics and Space Administration, 2010.

Muenkel, C., Leiterer, U., and Dier, H.-D.: Scanning the troposphere with a low-cost eye-safe lidar, in: Industrial Lasers and Inspection (EUROPTO Series), P. Soc. Photo-Opt. Ins., 2, 2-9, 1999.

Muenkel, C., Leiterer, U., and Dier, H.-D.: Affordable lidar for atmospheric aerosol and cloud studies, in: International Symposium on Optical Science and Technology, Seattle, Washington, USA, 7-11 July 2002, 198-206, 2002.

Pfalzgraff, W. C., Hulscher, R. M., and Neshyba, S. P.: Scanning electron microscopy and molecular dynamics of surfaces of growing and ablating hexagonal ice crystals, Atmos. Chem. Phys., 10, 2927-2935, doi:10.5194/acp-10-2927-2010, 2010.

Riédi, J., Goloub, P., and Marchand, R. T.: Comparison of POLDER cloud phase retrievals to active remote sensors measurements at the ARM SGP site, Geophys. Res. Lett., 28, 2185-2188, 2001.

Sassen, K.: The polarization lidar technique for cloud research: A review and current assessment, B. Am. Meteorol. Soc., 72, 18481866, 1991.

Sassen, K., Zhu, J., and Benson, S.: Midlatitude cirrus cloud climatology from the Facility for Atmospheric Remote Sensing, IV. Optical displays, Appl. Opt., 42, 332-341, 2003.

Shcherbakov, V.: Why the $46^{\circ}$ halo is seen far less often than the $22^{\circ}$ halo?, J. Quant. Spectrosc. Ra., 124, 37-44, 2013.

Shupe, M. D.: A ground-based multisensor cloud phase classifier, Geophys. Res. Lett., 34, L22809, doi:10.1029/2007GL031008, 2007.
Shupe, M. D., Uttal, T., and Matrosov, S. Y.: Arctic cloud microphysics retrievals from surface-based remote sensors at SHEBA, J. Appl. Meteorol., 44, 1544-1562, 2005.

Torres, B., Dubovik, O., Toledano, C., Berjon, A., Cachorro, V. E., Lapyonok, T., Litvinov, P., and Goloub, P.: Sensitivity of aerosol retrieval to geometrical configuration of ground-based sun/sky radiometer observations, Atmos. Chem. Phys., 14, 847875, doi:10.5194/acp-14-847-2014, 2014.

Turner, D. D., Ackerman, S., Baum, B., Revercomb, H. E., and Yang, P.: Cloud phase determination using ground-based AERI observations at SHEBA, J. Appl. Meteorol., 42, 701-715, 2003.

Um, J. and McFarquhar, G. M.: Single-scattering properties of aggregates of bullet rosettes in cirrus, J. Appl. Meteorol. Climatol., 46, 757-775, 2007.

Um, J. and McFarquhar, G. M.: Single-scattering properties of aggregates of plates, Q. J. Roy. Meteor. Soc., 135, 291-304, 2009.

Um, J., McFarquhar, G. M., Hong, Y. P., Lee, S.-S., Jung, C. H., Lawson, R. P., and Mo, Q.: Dimensions and aspect ratios of natural ice crystals, Atmos. Chem. Phys. Discuss., 14, 31111-31167, doi:10.5194/acpd-14-31111-2014, 2014.

van Diedenhoven, B.: The prevalence of the $22^{\circ}$ halo in cirrus clouds, J. Quant. Spectrosc. Ra., 146, 475-479, 2014.

van Diedenhoven, B., Cairns, B., Geogdzhayev, I. V., Fridlind, A. M., Ackerman, A. S., Yang, P., and Baum, B. A.: Remote sensing of ice crystal asymmetry parameter using multi-directional polarization measurements - Part 1: Methodology and evaluation with simulated measurements, Atmos. Meas. Tech., 5, 23612374, doi:10.5194/amt-5-2361-2012, 2012.

van Diedenhoven, B., Cairns, B., Fridlind, A. M., Ackerman, A. S., and Garrett, T. J.: Remote sensing of ice crystal asymmetry parameter using multi-directional polarization measurements Part 2: Application to the Research Scanning Polarimeter, Atmos. Chem. Phys., 13, 3185-3203, doi:10.5194/acp-13-31852013, 2013.

van Diedenhoven, B., Ackerman, A. S., Cairns, B., and Fridlind, A. M.: A Flexible Parameterization for Shortwave Optical Properties of Ice Crystals, J. Atmos. Sci., 71, 1763-1782, 2014.

Vermeulen, A., Devaux, C., and Herman, M.: Retrieval of the scattering and microphysical properties of aerosols from groundbased optical measurements including polarization: I. Method, Appl. Opt., 39, 6207-6220, 2000.

Welton, E. J., Campbell, J. R., Spinhirne, J. D., and Scott III, V. S.: Global monitoring of clouds and aerosols using a network of micropulse lidar systems, in: Second International Asia-Pacific Symposium on Remote Sensing of the Atmosphere, Lidar Remote Sensing for Industry and Environment Monitoring, Sendai, Japan, 9 October 2000, 4153, 151-158, 2001.

Westbrook, C. and Illingworth, A.: Evidence that ice forms primarily in supercooled liquid clouds at temperatures $>-27^{\circ} \mathrm{C}$, Geophys. Res. Lett., 38, L14808, doi:10.1029/2011GL048021, 2011.

Zrnic, D. S. and Ryzhkov, A. V.: Polarimetry for weather surveillance radars, B. Am. Meteorol. Soc., 80, 389-406, 1999. 